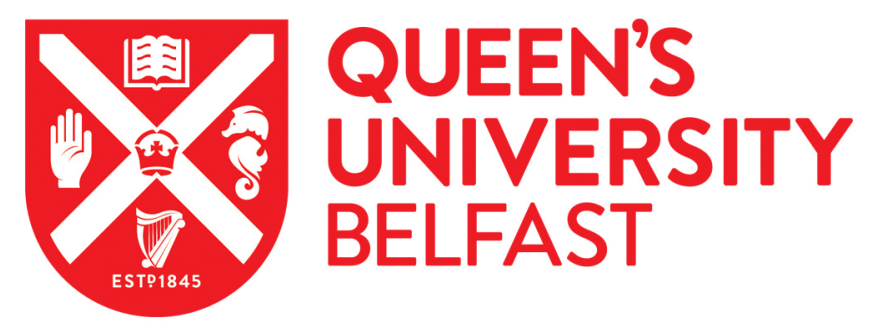

\title{
Battery energy storage system state-of-charge management to ensure availability of frequency regulating services from wind farms
}

Boyle, J., Littler, T., \& Foley, A. (2020). Battery energy storage system state-of-charge management to ensure availability of frequency regulating services from wind farms. Renewable Energy, 160. https://doi.org/10.1016/j.renene.2020.06.025

\section{Published in:}

Renewable Energy

\section{Document Version:}

Peer reviewed version

Queen's University Belfast - Research Portal:

Link to publication record in Queen's University Belfast Research Portal

\author{
Publisher rights \\ (c) Elsevier Ltd. \\ This manuscript version is made available under the CC-BY-NC-ND 4.0 license http://creativecommons.org/licenses/by-nc-nd/4.0/,which \\ permits distribution and reproduction for non-commercial purposes, provided the author and source are cited.
}

\section{General rights}

Copyright for the publications made accessible via the Queen's University Belfast Research Portal is retained by the author(s) and / or other copyright owners and it is a condition of accessing these publications that users recognise and abide by the legal requirements associated with these rights.

Take down policy

The Research Portal is Queen's institutional repository that provides access to Queen's research output. Every effort has been made to ensure that content in the Research Portal does not infringe any person's rights, or applicable UK laws. If you discover content in the Research Portal that you believe breaches copyright or violates any law, please contact openaccess@qub.ac.uk. 


\title{
Battery energy storage system state-of-charge management to ensure availability of frequency regulating services from wind farms
}

\author{
James Boyle \\ School of Electronics, Electrical Engineering and Computer Science \\ Queen's University Belfast, Northern Ireland \\ email: iboyle27@qub.ac.uk \\ Timothy Littler \\ School of Electronics, Electrical Engineering and Computer Science \\ Queen's University Belfast, Northern Ireland \\ email: tlittler@qub.ac.uk \\ Aoife M. Foley \\ School of Mechanical and Aerospace Engineering \\ Queen's University Belfast, Northern Ireland \\ email: afoley@qub.ac.uk
}

\begin{abstract}
State of charge management in battery energy storage systems will be imperative to ensure that frequency regulating services can be provided when required. Two state of charge controllers are proposed in this paper. One controller was designed to meet the charge/discharge requirements imposed on assets providing enhanced frequency response. The controller makes small corrective changes to the battery's power output to restore nominal charge. Simulation results show that the controller is effective at restoring nominal charge when the deviation from nominal is small. However, when the charge is significantly high or low, operating within the confines of the enhanced frequency response service envelope will lead to long periods where the charge is above or below nominal. This will reduce the availability of frequency regulating services from the system. A second controller is proposed to accelerate the restoration of nominal charge. The controller is intended for use in wind farms that have an integrated battery energy storage system, whereby hybrid dispatch control can be employed. The objective of hybrid control is to create a power exchange between the wind turbine and battery system to accelerate nominal charge restoration, without significantly impacting the system frequency and the wind farm's output.
\end{abstract}

\section{Keywords}

Battery energy storage; wind generation; frequency control; state of charge control; fuzzy logic control.

\section{Acronyms}

BESS Battery energy storage system

DFIG Doubly fed induction generator

EFR Enhanced frequency response

FFR Fast frequency response 


$\begin{array}{lll}44 & \text { PAC } & \text { Pitch angle control } \\ 45 & \text { POR } & \text { Primary operating reserve } \\ 46 & R & \text { Percentage droop } \\ 47 & \text { SoC } & \text { State of charge } \\ 48 & \text { SOR } & \text { Secondary operating reserve } \\ 49 & & \end{array}$

\section{Symbols}

$51 f_{\text {meas }} \quad$ Measured frequency

$52 f_{\text {nom }} \quad$ Nominal frequency

$53 \quad K_{D} \quad$ Droop constant

$54 \quad K_{S o C} \quad$ Accelerated state of charge recovery controller gain

$55 \quad N_{p} \quad$ Number of cells in parallel

$56 \quad N_{s} \quad$ Number of cells in series

$57 \quad P_{D} \quad$ Droop controller output

$58 \quad P_{F L C} \quad$ Fuzzy logic controller output

$59 P_{\text {max }}$ Bess Active power rating of battery energy storage system

$60 \quad P_{\text {max }}$ wT Maximum power available from wind turbine

$61 \quad P_{\text {order }}$ BESS power order

$62 \quad P_{R} \quad$ Wind turbine active power reserve

$63 \quad P_{R_{-} P A C} \quad$ Power offset setpoint

$64 \quad P_{S o C} \quad$ Accelerated state of charge recovery controller output

$65 Q_{c} \quad$ Charge capacity

$66 S_{\max } \quad$ Battery energy storage system apparent power rating

$67 \quad S_{0} C_{S P} \quad$ State of charge setpoint

$68 V_{c \max } \quad$ Maximum cell voltage

$69 V_{\text {cmin }} \quad$ Minimum cell voltage

$70 \quad \beta \quad$ Blade pitch angle

$71 \quad \beta_{\max } \quad$ Maximum blade pitch angle

$72 \quad \beta_{\min } \quad$ Minimum blade pitch angle

$73 \beta_{\text {offset }} \quad$ Blade pitch angle offset

$74 \Delta f \quad$ Frequency deviation

$75 \Delta \beta \quad$ Change in blade pitch angle

$76 \Delta \beta_{\text {lim }} \quad$ Change in blade pitch angle (limited)

$77 \Delta \beta_{\max } \quad$ Maximum rate of change in blade pitch angle

$78 \Delta \beta_{\min } \quad$ Minimum rate of change in blade pitch angle

$79 \Delta \omega \quad$ Speed error

$80 \omega_{\max } \quad$ Maximum rotor speed

$81 \omega_{\text {meas }} \quad$ Measured rotor speed

\section{Units}

84 Ah Ampere-hour

$85 \mathrm{~Hz} \quad$ Hertz 


$\begin{array}{lll}86 & \text { MVA } & \text { Mega-volt-ampere } \\ 87 & \text { MW } & \text { Mega-watt } \\ 88 & \text { pu } & \text { Per-unit } \\ 89 & \text { s } & \text { Second } \\ 90 & \text { V } & \text { Voltage } \\ 91 & & \end{array}$

As the penetration of non-synchronous generation increases on the power system, the negative influence that load-generation imbalances have on the system frequency will be exacerbated [1], [2]. The availability of reliable system (ancillary) services will be imperative to ensure that system stability is always maintained. System services procured from intermittent, renewable generation, such as wind, will be less reliable than those procured from conventional thermal or hydro generation. Battery energy storage systems (BESSs) integrated into wind farms could increase the reliability of ancillary services by reducing intermittency [3]. This could open new income streams for wind farms by enabling them to offer system services to grid operators.

Currently, the power system on the island of Ireland (i.e. iSEM) is heavily dependent on interconnection with the power system in England, Scotland and Wales (i.e. referred to as the BETTA) to provide essential system services such as primary operating reserve (POR) and secondary operating reserve (SOR) [4], [5]. If wind generation and BESSs could provide these services, then it would reduce Ireland's dependence on interconnection with the United Kingdom and other European countries. With advances in battery technologies [6], [7], battery energy storage has been considered as being suitable for providing frequency regulating services that operate in the short to medium timescales (1s -15 minutes) after a frequency event [8]. Such services would include enhanced frequency response (EFR), fast frequency response (FFR) and POR.

Recent studies have investigated BESS's ability to provide frequency regulating services [9][12]. An investigation into the speed of response of a 10MW BESS in Kilroot Power Station in Northern Ireland, shows that the installed BESS can increase its output from zero to maximum in less than 1.5s [13]. The speed of response of BESSs make them suitable for providing FFR and EFR services [9]. Coordinated BESS and wind turbine control schemes have been investigated in [10], [11]. In [10], a control scheme is proposed that uses coordinated control of a BESS and permanent magnet synchronous generator wind turbine to eliminate a secondary frequency dip during rotor speed recovery, while the use of redox flow batteries in coordination with emulated inertia from a wind turbine is investigated in [11]. S. Dhundhara et al. [11] show that the coordinated responses from the redox flow batteries and wind turbine can reduce stress on the wind turbine during emulated inertial response. The redox flow batteries can also be used to absorb excess power through transmission lines to reduce wind curtailment.

It is well documented that BESS can provide frequency regulating services within a very short timeframe. If BESSs are to participate in frequency regulation successfully, then the state of charge (SoC) must be maintained nominally at $0.5 \mathrm{pu}$. Maintaining the $\mathrm{SoC}$ at $0.5 \mathrm{pu}$ means that the BESS can respond to under-frequency and over-frequency events equally, i.e. the BESS has equal charge and discharge capacity. If the $\mathrm{SoC}$ is greater than $0.5 \mathrm{pu}$, then the BESS will have greater capacity to provide under-frequency regulation, but reduced capacity to provide overfrequency regulation. Conversely, if the SoC is less than $0.5 \mathrm{pu}$, then the BESS will have greater capacity to provide over-frequency regulation, but lower capacity to provide under-frequency 
regulation. Maintaining the $\mathrm{SoC}$ close to $0.5 \mathrm{pu}$ may also have the added benefit of increasing the life expectancy of the battery cells [14], [15]. It will be imperative that the BESS SoC is effectively managed to ensure that contracted frequency regulating services can be provided before the next service delivery.

More recent studies have highlighted SoC recovery after a frequency event as being an area of importance. In [16], a battery energy management strategy is proposed that allows the BESS to be charged, within the confines of the charge/discharge limitations imposed on assets providing EFR, for 30 minutes immediately after service delivery. However, no indication is given as to how the power set-point during the restoration period is achieved. The authors highlight the importance of $\mathrm{SoC}$ restoration to increase the availability of frequency regulation responses from BESSs and to avoid service performance measure non-conformance penalties [8]. In [12], [17], adaptive SoC feedback controllers are used to re-establish the BESS SoC. This is achieved by varying the adaptive parameter as a function of the measured $\mathrm{SoC}$ when the system frequency is within a dead-band.

This paper addresses SoC restoration to increase the availability of system services by presenting two controllers that work to restore nominal SoC after a frequency event. One controller makes small corrective changes to the BESS power flow to restore nominal SoC. These corrective changes are achieved using fuzzy logic control. Unlike the SoC recovery controllers mentioned in the literature above, the proposed controller uses any additional charge/discharge capacity to increase the BESS's response to frequency events. This accelerates the restoration of nominal SoC, while providing additional frequency regulation. The second controller is intended for use in wind farms that have a BESS. The objective of the controller is to reduce the impact that SoC recovery has on the system frequency by creating a power exchange between the wind turbine and BESS to assist SoC recovery. The power exchange reduces the impact on the system frequency and the power flow between the wind farm and the grid. This work is novel in that it not only examines SoC recovery when close to nominal charge but also when close to full discharge/charge, whereas other research focuses on $\mathrm{SoC}$ recovery when there is a small deviation from nominal charge. The difference in this work to others is very important for wind farm owners and grid operators in terms of system services in power systems with large penetrations of variable renewable energy (e.g. wind) because it demonstrates that nominal SoC can be re-established quickly after a frequency event without significantly impacting system frequency. Note, for the purposes of this work, a BESS is taken to be a battery device, the associated converters, and controllers.

The remainder of this paper is structured as follows. Section 2 gives an overview of operational requirements for BESS in Ireland, Northern Ireland, and the United Kingdom. Section 3 gives a detailed description of the BESS active power controller, which includes details of the proposed fuzzy logic and accelerated SoC recovery controllers. Section 4 presents the wind turbine model and shows how the pitch controller can be modified to allow the wind turbine to provide delta reserve, frequency-droop control, and charge recovery assistance to the BESS. Section 5 presents the modified IEEE 39-bus power system model that was built in DIgSILENT PowerFactory to produce the results presented in Section 6. The results are analysed in Section 6 and discussed in Section 7. Finally, Section 8 concludes, summarises the key findings and identifies knowledge learned and next steps in the work.

\section{Battery Energy Storage System Operational Requirements}

175 Currently, there are no obligatory operational requirements defined by the ENTSO-E relating 176 to SoC management for BESSs or indication as to how the restoration of nominal SoC after 
The requirements outlined in future European codes will inform National level grid codes for individual countries. In Ireland and Northern Ireland, BESSs must follow the frequency response curve shown in Figure 1.

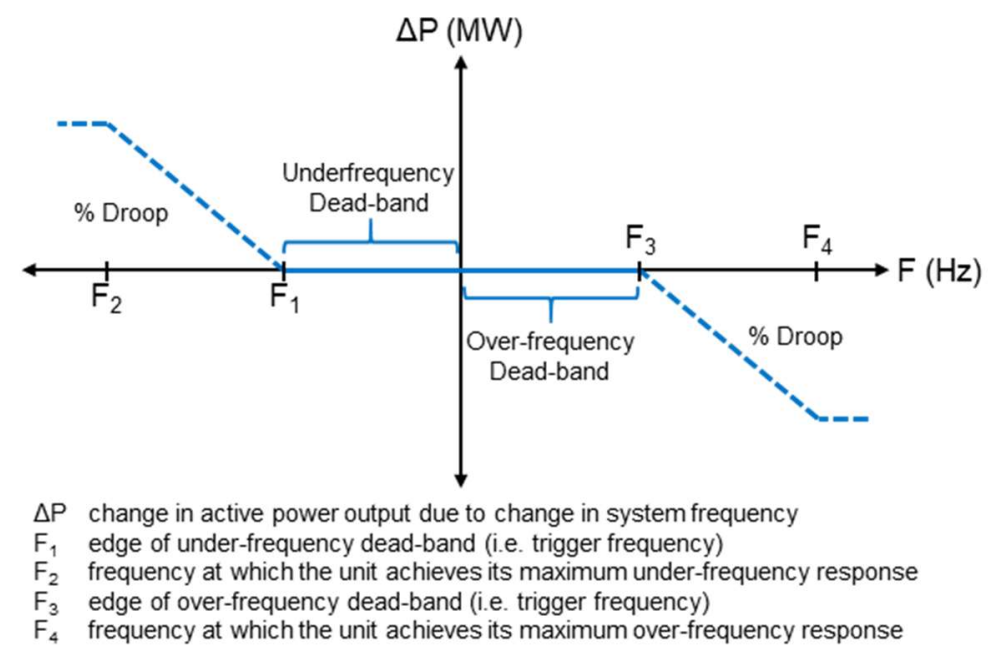

Figure 1. Frequency response of BESS as defined in [18]

The dead-band limits shall be settable between $49.5-49.985 \mathrm{~Hz}$ for under-frequency $\left(\mathrm{F}_{1}\right)$ and $50.015-50.5 \mathrm{~Hz}$ for over-frequency $\left(\mathrm{F}_{2}\right)$. The BESS delivers active power during underfrequency conditions and absorbs active power during over-frequency conditions. There are currently no requirements outlined in grid codes in Ireland [19] and Northern Ireland [20], defining how nominal SoC should be re-established after service delivery. A similar situation exists in the United Kingdom, where BESS specific operational requirements regarding the reestablishment of nominal SoC are yet to be specified. If the deployment of BESSs is to increase to significant levels, then SoC management will be imperative to ensure that the system can provide its contracted post-contingency service when required.

193 A new system service has been introduced in the United Kingdom called enhanced frequency 194 response (EFR). Enhanced frequency response is intended to serve two purposes. Under normal operation, it is intended to maintain system frequency closer to its nominal value of $50 \mathrm{~Hz}$. While post-contingency, EFR provides dynamic frequency support proportional to frequency deviation for a period not less than 15 minutes. Assets providing EFR must deliver continuous active power within one of two service envelopes (see Figure 2). Service 1 has an envelope with a frequency deviation dead-band of $\pm 0.05 \mathrm{~Hz}$. Service 2 has an envelope with a frequency deviation dead-band of $\pm 0.015 \mathrm{~Hz}$. Service 2 has the most value to the grid operator due to the smaller dead-band. 


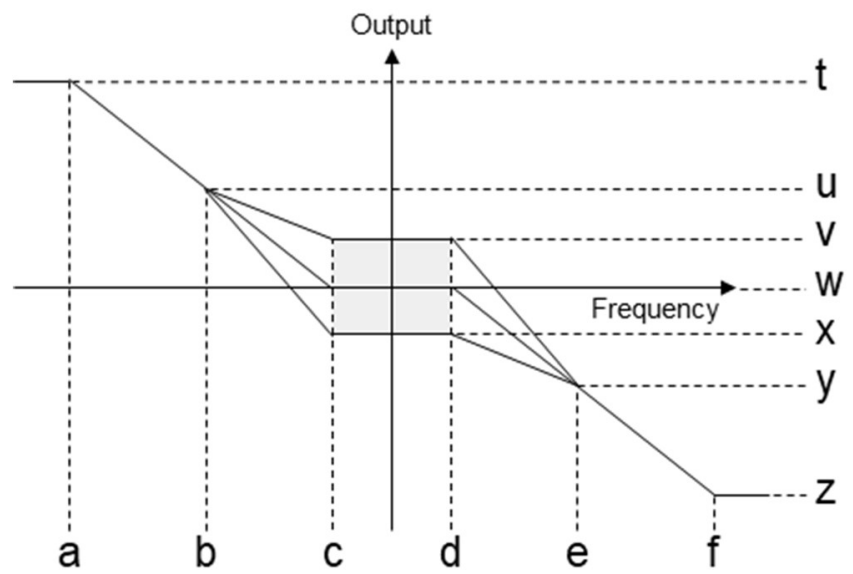

(a)

\begin{tabular}{|c|c|c|}
\hline $\begin{array}{c}\text { Reference } \\
\text { Point }\end{array}$ & $\begin{array}{c}\text { Service 1 } \\
{[\mathrm{Hz}]}\end{array}$ & $\begin{array}{c}\text { Service 2 } \\
{[\mathrm{Hz}]}\end{array}$ \\
\hline $\mathrm{A}$ & 49.50 & 49.500 \\
\hline $\mathrm{B}$ & 49.75 & 49.750 \\
\hline $\mathrm{C}$ & 49.95 & 49.985 \\
\hline $\mathrm{D}$ & 50.05 & 50.015 \\
\hline $\mathrm{E}$ & 50.25 & 50.250 \\
\hline $\mathrm{F}$ & 50.50 & 50.500 \\
\hline
\end{tabular}

(b)

\begin{tabular}{|c|c|c|}
\hline $\begin{array}{c}\text { Reference } \\
\text { Point }\end{array}$ & $\begin{array}{c}\text { Service 1 } \\
{[\% \text { Capacity] }}\end{array}$ & $\begin{array}{c}\text { Service 2 } \\
{[\% \text { Capacity] }}\end{array}$ \\
\hline $\mathrm{t}$ & $100 \%$ & $100 \%$ \\
\hline $\mathrm{u}$ & $44.44444 \%$ & $48.45361 \%$ \\
\hline $\mathrm{v}$ & $9 \%$ & $9 \%$ \\
\hline $\mathrm{w}$ & $0 \%$ & $0 \%$ \\
\hline $\mathrm{x}$ & $-9 \%$ & $-9 \%$ \\
\hline $\mathrm{y}$ & $-44.44444 \%$ & $-48.45361 \%$ \\
\hline $\mathrm{z}$ & $-100 \%$ & $-100 \%$ \\
\hline
\end{tabular}

Figure 2. Service envelope for assets providing EFR as defined in [8]: (a) Reference points in Hz (b) Reference points as \% of active power output

Assets providing EFR can vary their active power output by $\pm 9 \%$ of their maximum rating when the system frequency is within the dead-band. For BESSs, which accounted for $68 \%$ of total tender submissions [8], this allows the $\mathrm{SoC}$ to be managed. As battery projects accounted for a significant amount of the submissions to an EFR invitation to tender, and no other operational specific requirements for BESS have become standardised in Ireland and the United Kingdom, the BESS active power controller proposed in Section 3 was designed to operate within the confines of the EFR service 2 envelope.

\section{Battery Energy Storage Active Power Control}

Figure 3 shows the BESS active power controller built in DIgSILENT PowerFactory. The active power controller comprises three component controllers, the droop controller, the fuzzy logic controller and the accelerated SoC recovery controller. The active power order, $P_{\text {order }}$, is the summation of the component controllers' outputs and is used to control the BESS's active power output. When $P_{\text {order }}$ is negative, the BESS absorbs active power by charging. When positive, it delivers active power by discharging. 


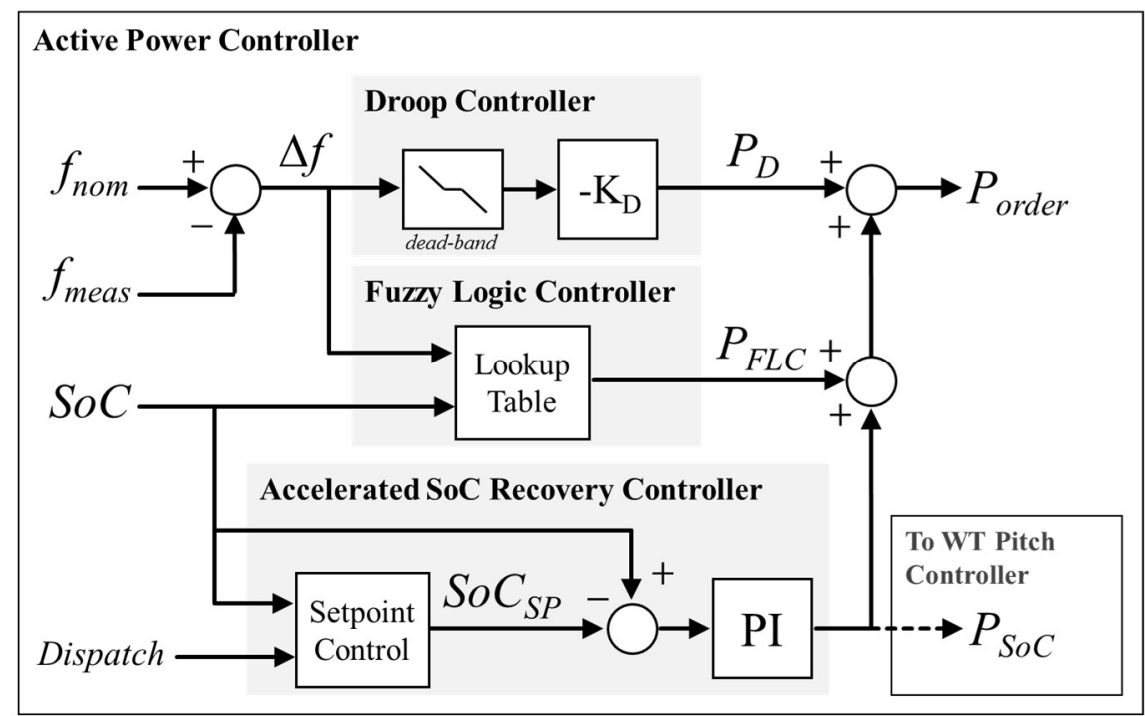

Figure 3. BESS active power controller

\section{$222 \quad 3.1 \quad$ Frequency-droop controller}

The output of the droop controller, $P_{D}$, varies as a linear function of system frequency deviation $(\Delta f)$ when the frequency deviation dead-band is exceeded. This provides frequency-droop regulation. The BESS will charge when $\Delta f$ is positive and discharge when $\Delta f$ is negative [21]. The droop constant, $K_{D}$, defines the slope of the frequency-droop characteristic. If $\Delta f$ exceeds the dead-band, then $P_{D}=-K_{D} \Delta f$. If $\Delta f$ is within the dead-band, then $P_{D}$ is zero. The fuzzy logic controller and the accelerated SoC recovery controller shown in Figure 3 will be discussed in the following sections.

\subsection{Fuzzy logic controller}

The output of the fuzzy logic controller, $P_{F L C}$, is used to make small corrective changes $(\leq 9 \%$ of the BESS rating) to the BESS power flow to re-establish nominal charge. The controller was implemented in DIgSILENT PowerFactory using a lookup table. The lookup table was generated in MATLAB using a script that looped through all possible input combinations of a fuzzy inference system. The fuzzy rules used are shown in Table 1.

Table 1. Fuzzy rules. Frequency deviation: $B N=$ big negative, $S N=$ small negative, $Z=$ zero, $S P=$ small positive, $B P=$ big positive. SoC: $V L=$ very low, $L=$ low, $M=$ medium, $H=$ high, $V H=$ very high. Output: $\mathrm{BD}=$ big discharge, $\mathrm{SD}=$ small discharge, $\mathrm{Z}=$ zero, $\mathrm{SC}=$ small charge, $\mathrm{BC}=$ big charge

\begin{tabular}{|c|c|c|c|c|c|c|}
\hline & \multicolumn{5}{|c|}{ Frequency deviation } \\
\hline & & BN & SN & $\mathbf{Z}$ & SP & BP \\
\hline \multirow{5}{*}{ : } & VL & $\mathrm{Z}$ & $\mathrm{SC}$ & $\mathrm{BC}$ & $\mathrm{BC}$ & $\mathrm{BC}$ \\
\hline & $\mathbf{L}$ & $\mathrm{Z}$ & $\mathrm{SC}$ & $\mathrm{BC}$ & $\mathrm{SC}$ & $\overline{\mathrm{BC}}$ \\
\hline & $\mathbf{M}$ & $\mathrm{Z}$ & Z & $\mathrm{Z}$ & $\mathrm{Z}$ & $Z$ \\
\hline & $\mathbf{H}$ & $\mathrm{BD}$ & $\mathrm{BD}$ & $\mathrm{BD}$ & SD & $Z$ \\
\hline & VH & $\mathrm{BD}$ & $\mathrm{BD}$ & $\mathrm{BD}$ & SD & $\mathrm{Z}$ \\
\hline
\end{tabular}


242 The input and output membership functions are shown in Figure 4.
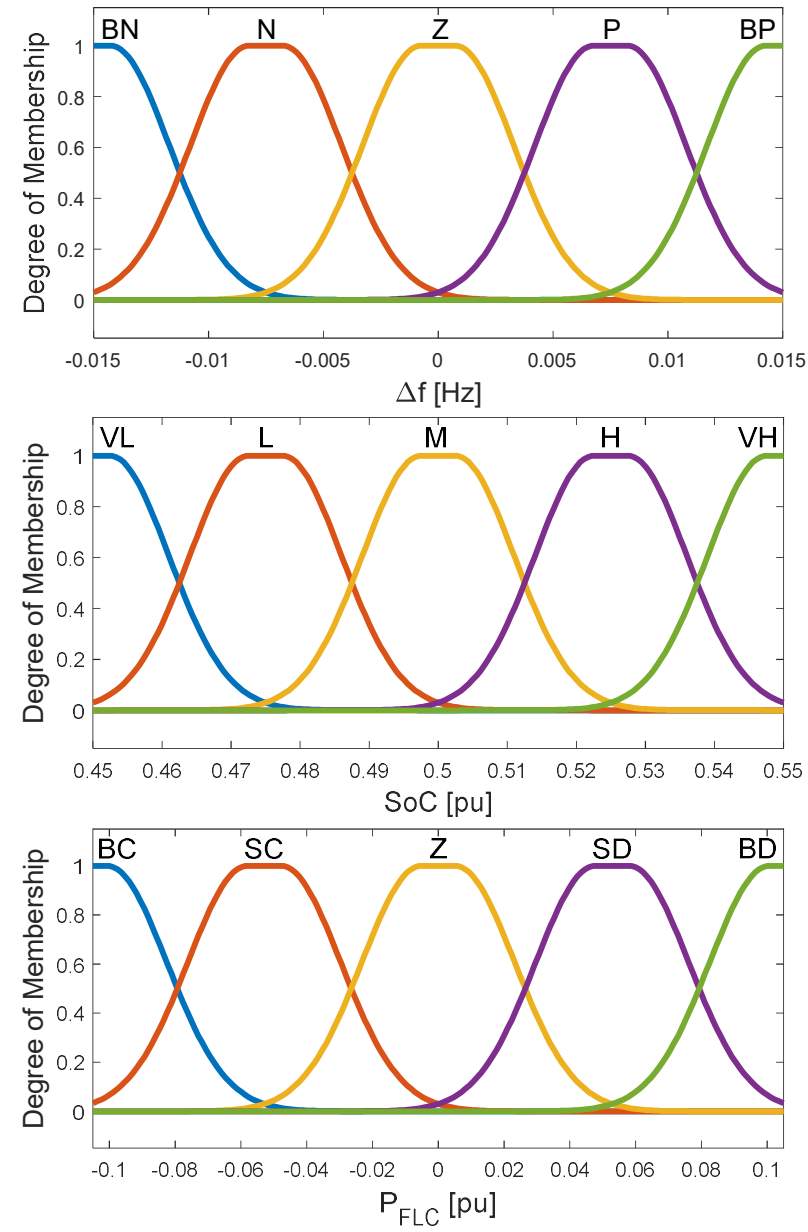

Figure 4. Fuzzy inference system input and output membership functions

The output is produced using the centroid defuzzification method. The surface plots (i.e. surface 248 plot of $P_{F L C}$ against SoC and $\Delta f$ ) are shown in Figure 5.

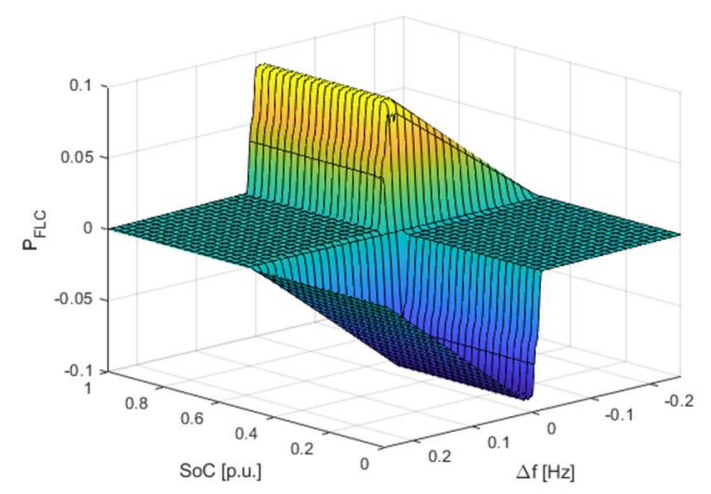

(a)

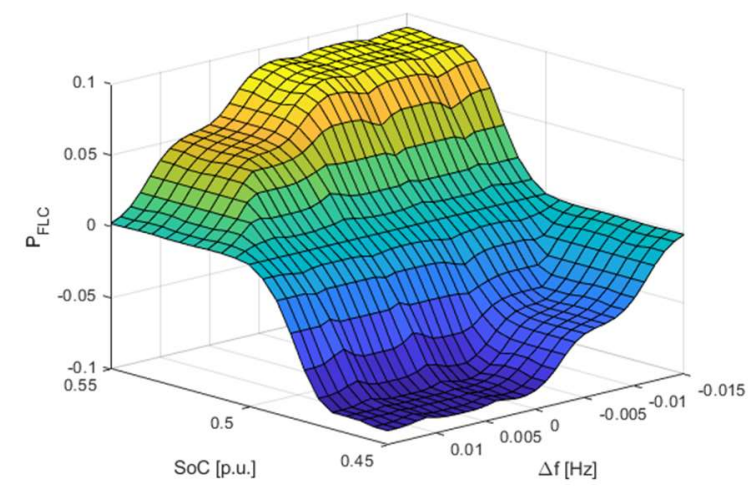

(b)

Figure 5. Fuzzy inference system surface plot: (a) SoC range 0 to 1 pu, $\Delta$ f range -0.25 to 0.25 (b) SoC range 0.45 to $0.55 \mathrm{pu}, \Delta$ f range -0.015 to $0.015 \mathrm{~Hz}$ 
When $P_{F L C}$ is negative, the BESS will charge. When positive, the BESS will discharge. With reference to the surface plots, the BESS will charge when the SoC is below $0.5 \mathrm{pu}$ and the system frequency is greater than nominal. The BESS will discharge when the SoC is greater than $0.5 \mathrm{pu}$ and the system frequency is below nominal. It can be noted that the controller becomes fully deactivated when the system frequency deviation reaches $\pm 0.25 \mathrm{~Hz}$ (i.e. $P_{F L C}$ converges to zero at $\Delta f= \pm 0.25 \mathrm{~Hz}$ ), and the magnitude of $P_{F L C}$ is limited to $0.09 \mathrm{pu}$, when the frequency deviation is within the $\pm 0.015 \mathrm{~Hz}$ dead-band (Figure 5 (b)). These two design criteria ensure that the BESS operates within the confines of the EFR service 2 envelope as discussed in Section 2.

If the Ah rating of the BESS is such that full discharge occurs, from nominal SoC, after full power delivery for 15 minutes, then the BESS would take a minimum of 2 hours and 47 minutes to restore its nominal charge after a service delivery using recovery control schemes that adhere to the charge/discharge restrictions imposed on assets providing EFR. This minimum re-charge duration has been determined by assuming that the BESS is charging at $9 \%$ of its power rating and that the frequency is within the dead-band for the entirety of the charging period (i.e. 15/0.09 minutes). The calculation of the minimum re-charge duration assumes that only the nominal charge restoration control scheme is used to restore nominal charge. Obviously, any over-frequency regulating response from the BESS would reduce the re-charge time.

If the SoC is very low and a significant under-frequency event occurs, the BESS may not have enough charge to provide its contracted frequency response, which could result in service performance measure non-conformance penalties, unless the BESS Ah rating is significantly overrated. Similarly, if the SoC is very high and a significant over-frequency event occurs, the BESS will have limited charging capacity because the SoC is already very high.

If service performance measure non-conformance penalties are to be avoided, then a BESS should not sustain a SoC outside the nominal range for significant periods. This highlights the need for accelerated SoC recovery. The accelerated SoC recovery controller proposed in the following section (Section 3.3) is intended to be used to quickly re-establish nominal charge in cases where the control scheme presented in this section would lead to very long recovery times, (i.e. when the SoC is very high or very low).

\section{$281 \quad 3.3 \quad$ Accelerated State of Charge Recovery Controller}

The accelerated SoC recovery control scheme will be discussed in the following sub-sections. The control scheme can operate autonomously, however, hybrid dispatch control of a wind farm and BESS is investigated to show that the accelerated recovery scheme can be implemented without significantly impacting on system frequency. Though the control scheme presented applies to wind farms with integrated battery energy storage, the same principle could be applied to other generation sources such as thermal, hydro, or solar photovoltaic generation.

\subsubsection{Implementation}

Accelerated SoC recovery is achieved by controlling the SoC setpoint, $S_{O} C_{S P}$, in the BESS active power controller (see Figure 3 and Figure 6). During normal operation, $S_{S} C_{S P}$ is set to the measured SoC. This means that $S_{0} C_{S P}$ follows the SoC, essentially making the accelerated recovery controller inactive, allowing the BESS to charge or discharge as required by the frequency-droop and fuzzy logic controllers. When the SoC is significantly high or low, a dispatch signal is used to change $S o C_{S P}$ to the nominal value of $0.5 \mathrm{pu}$. Dispatching can be manual or automatic (e.g. when the SoC reaches a certain threshold). The rate of change of $S o C_{S P}$ is limited using a ramp function to prevent a sudden frequency excursion. A proportionalintegral (PI) controller is used to generate the controller output $P_{S o C}$. 


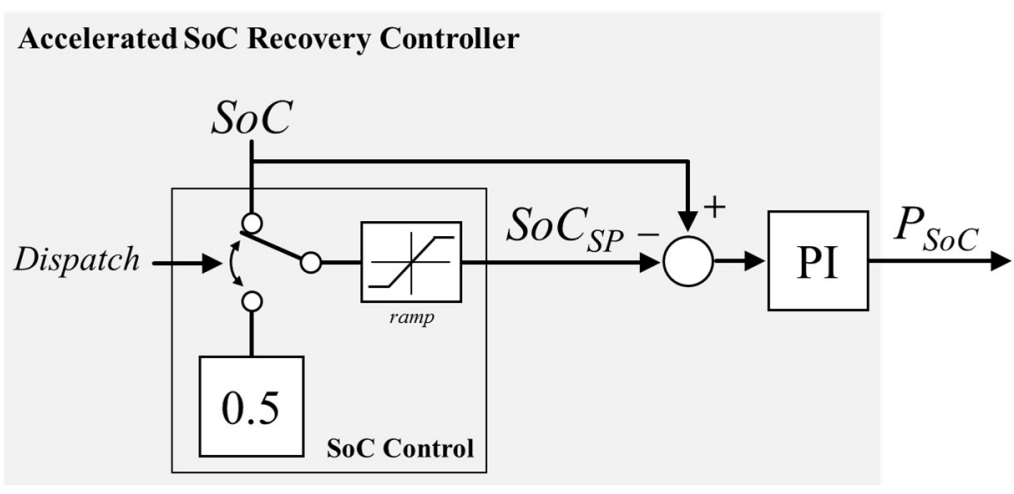

Figure 6. Accelerated SoC recovery controller

\subsubsection{Hybrid Control}

Hybrid dispatch control is intended to reduce the impact that accelerated SoC recovery has on the system frequency. Hybrid operation of the BESS and wind turbine is achieved by sending $P_{S o C}$ (output of the controller in Figure 6) to the wind turbine blade pitch controller to change the blade pitch angle (blade pitch controller is discussed in Section 4). If the SoC is below nominal, $P_{S o C}$ will be negative, which will cause the BESS to charge. The same signal is scaled and added to the wind turbine blade pitch angle setpoint to decrease the wind turbine's blade pitch angle, which increases the wind turbine's active power output. It should be noted that this control scheme is proposed for use with wind turbines that are operating with an active power reserve that is achieved using pitch angle control. Therefore, the blade pitch angle will be greater than zero under normal operation. Scaling the control signal $P_{S o C}$ so that the charging power is equal to the wind turbine's increase in power reduces the impact that accelerated SoC recovery has on the system frequency. If the BESS SoC is very high, the BESS must be discharged. When the $\mathrm{SoC}$ is greater than nominal, $P_{S o C}$ will be positive, which will cause the BESS to discharge. Simultaneously, the positive $P_{S o C}$ value will be scaled, and added to the wind turbine's blade pitch angle setpoint to decrease the wind turbine's active power output.

\section{$4 \quad$ Wind Turbine Model}

The wind turbine was modelled as a type 3, doubly fed induction generator (DFIG) [22]. The active power output and speed of DFIG wind turbines are usually limited using blade pitch angle control. Pitch angle control can also be used to de-load wind turbines, thereby creating reserve that can be used to provide frequency regulation [23]-[26]. Reserve in wind turbines can be categorised as either balance or delta [27], [28]. With balance control, the wind turbine's active power reference is set to a constant value below the maximum available power. The amount of reserve is not constant and varies as the maximum available power varies. With delta control, a constant power or percentage reserve is maintained.

Figure 7 shows the control diagram of a variable speed wind turbine blade pitch angle controller. The error between the wind turbine's maximum speed, $\omega_{\max }$, and the measured speed, $\omega_{\text {meas }}$, is used as the input to a proportional-integral controller to give the pitch angle setpoint, $\beta_{\text {set. }}$. The set-point is limited to the range $\beta_{\min }$ to $\beta_{\max }$. When the rotor speed is less than rated speed, the blade pitch angle is $\beta_{\min }\left(\beta_{\min }\right.$ is set to $\left.0^{\circ}\right)$. If the speed increases beyond $\omega_{\max }$, then $\beta_{\text {set }}$ will increase to reduce the wind turbine's active power output and speed. The supplementary control loops (shaded area in Figure 7) added to the blade pitch controller provide active power operating reserve (percentage delta reserve), frequency-droop regulation, and assisted SoC recovery. 


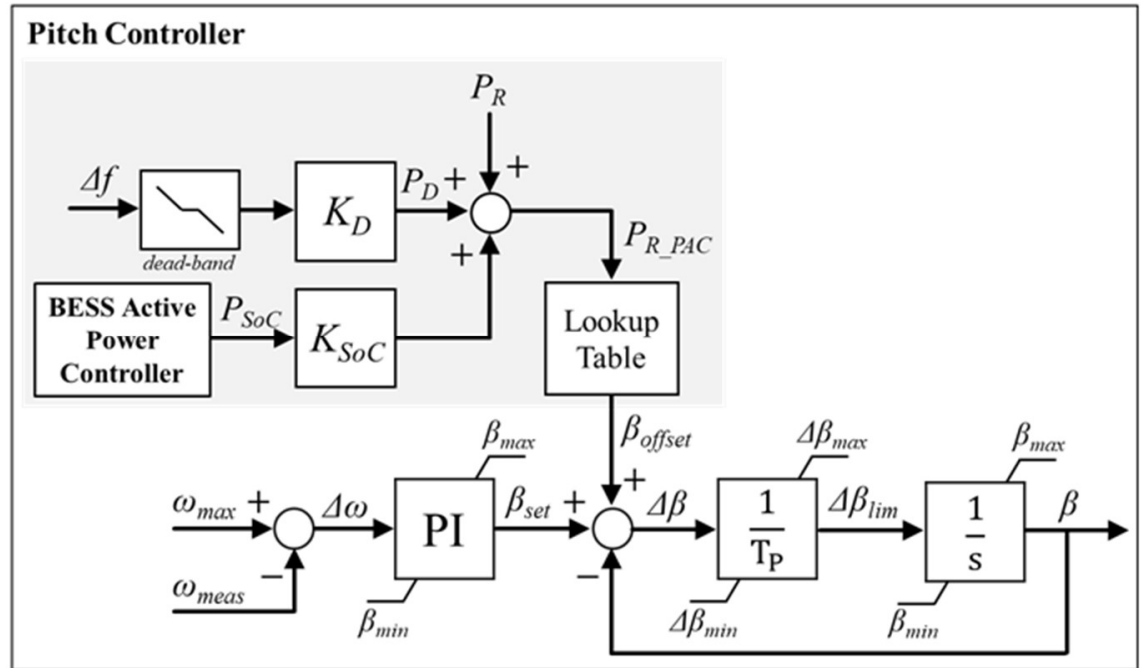

Figure 7. Wind turbine blade pitch angle controller

\section{$336 \quad 4.1 \quad$ Operating Reserve}

337 Operating reserve is achieved by adding an offset, $\beta_{\text {offset }}$, to $\beta_{\text {set }}$. The offset increases the blade pitch angle, thereby decreasing the wind turbine's power extraction from the incident wind. A lookup table that relates power reserve, $P_{R} P A C$, to the blade pitch angle was created in MATLAB using a while-loop. The flowchart representation of the MATLAB script is shown in Figure 8. The script calculates the per-unit power reserve $P_{R} P A C$ that results from incremental changes in blade pitch angle, $\beta$, and stores the result in a matrix. The elements of this matrix were used to populate the $\left(P_{R_{-}} P A C-\beta\right)$ lookup table shown in Figure 7.

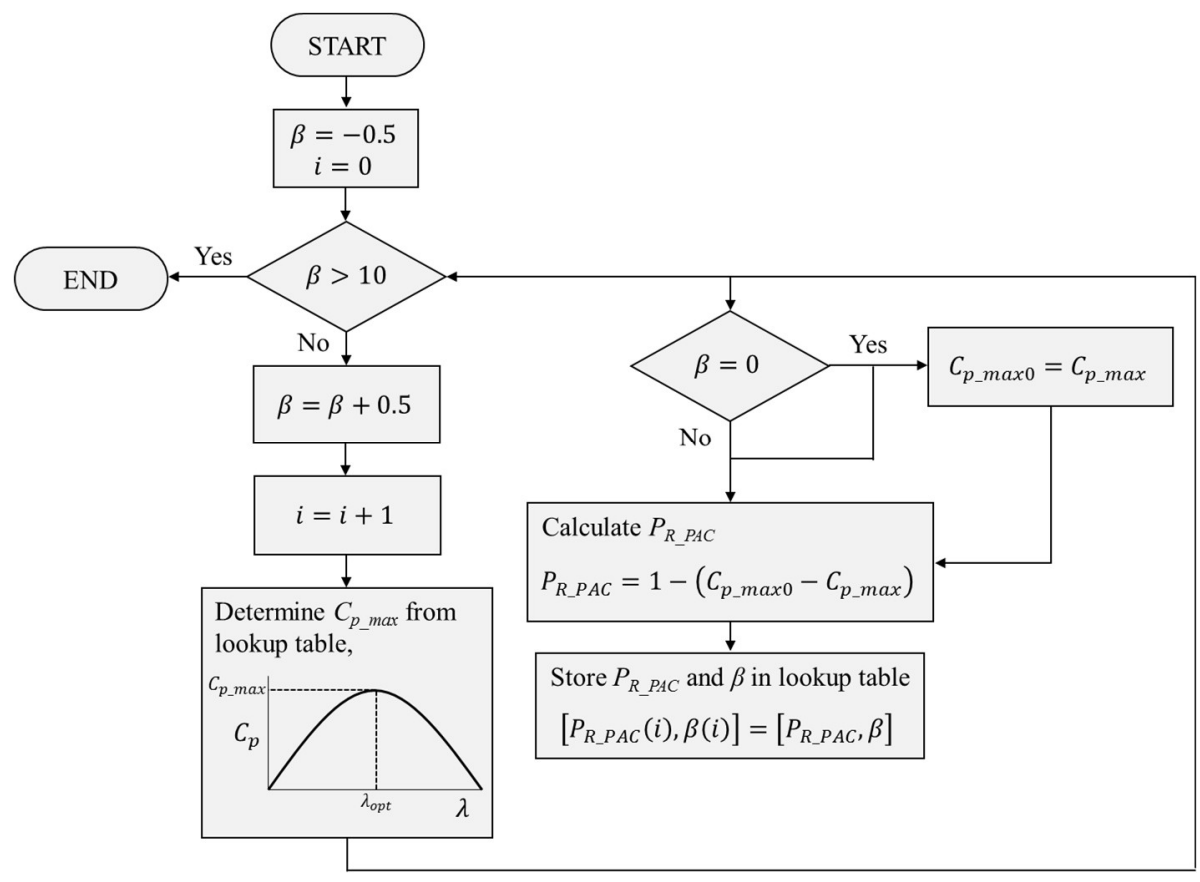

Figure 8. Flowchart representation of MATLAB script used to create $\left(P_{R_{-} P A C}-\beta\right)$ lookup table 
347 The power coefficient to tip speed ratio $\left(C_{p}-\lambda\right)$ lookup table shown in Figure 8 was created in 348 MATLAB using a script that calculates $C_{p}(\lambda, \beta)$ using varying values of $\lambda$ and $\beta$ according to 349 [29],

350

$$
C_{p}(\lambda, \beta)=0.5176\left(116 / \lambda_{i}-0.4 \beta-5\right) e^{-21 / \lambda_{i}}+0.0068 \lambda
$$

351

352 where,

$$
\lambda_{i}=\left(\frac{1}{\lambda+0.08 \beta}-\frac{0.035}{\beta^{3}+1}\right)^{-1}
$$

353

354 The script stores the resultant $C_{p}$ values in a lookup table. The flowchart representation of the 355 script is shown in Figure 9.

356

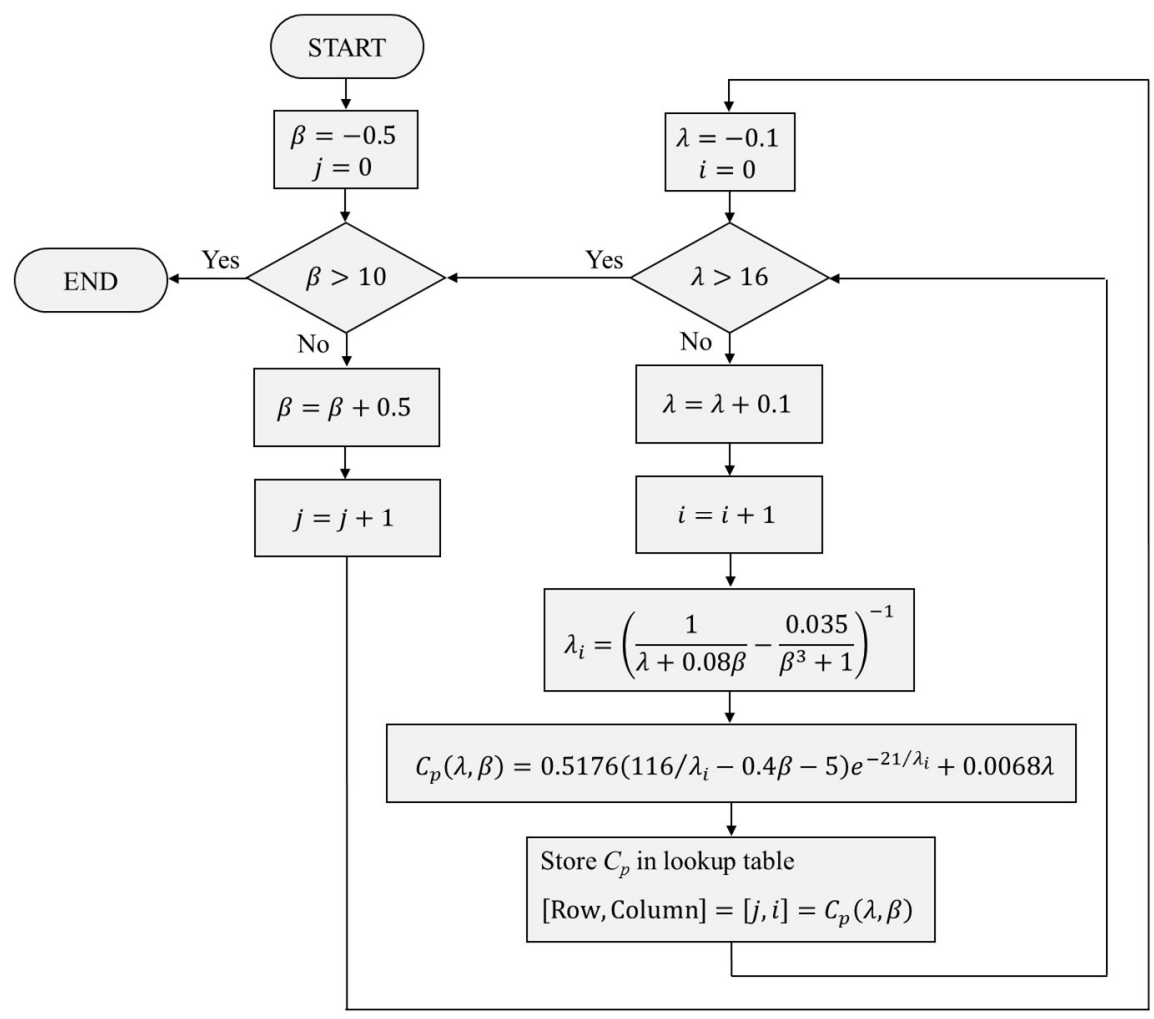




\subsection{Frequency-Droop Regulation}

Frequency-droop control is implemented by adding $P_{D}$ to the per-unit active power reserve setpoint, $P_{R}$. A dead-band is used to prevent activation of the frequency-droop controller when the system frequency is within normal limits. If the magnitude of the frequency deviation exceeds the dead-band, then $P_{D}$ will vary proportionally to frequency deviation, according to (3). If the magnitude of the frequency deviation is within the dead-band, then $P_{D}$ will be equal to zero.

$$
P_{D}=\left\{\begin{array}{cc}
\Delta f K_{D}, & |\Delta f|>\text { deadband } \\
0, & |\Delta f| \leq \text { deadband }
\end{array}\right.
$$

369

370

371

372

373

374

Negative $\Delta f$, outside of the dead-band, will decrease $\beta_{\text {offset }}$, reducing the blade pitch angle. This will increase the wind turbine's active power output, utilising some or all the reserve depending on the magnitude of the frequency deviation. Positive $\Delta f$, outside of the dead-band, will increase the blade pitch angle, thus increasing the spillage of wind, and decreasing the active power output of the wind turbine. The droop constant $K_{D}$ shown in Figure 7 sets the slope of the frequency-droop characteristic. The droop constant can be calculated as,

$$
K_{D}=\frac{1}{\left(\frac{R}{100}\right) \times f_{\text {nom }}}
$$

where, $R$ is percentage droop, and $f_{\text {nom }}$ is the nominal frequency. The Irish Grid Code [19] stipulates that wind turbines must operate according to a frequency-droop characteristic settable between $2-10 \%$ and defaulting at $4 \%$ when the system frequency deviation is outside the $\pm 0.015 \mathrm{~Hz}$ dead-band. The grid code in Northern Ireland [20] also stipulates a $\pm 0.015 \mathrm{~Hz}$ deadband and default frequency droop setting of $4 \%$ for generators. In the simulations performed, $K_{D}$ was set to 0.5 to provide $4 \%$ frequency-droop regulation, and the dead-band was set to $\pm 0.015 \mathrm{~Hz}$.

\subsection{Assisted State of Charge Recovery}

Assisted SoC recovery is achieved using hybrid dispatch control of the wind turbine and BESS. The signal $P_{S o C}$ from the BESS active power controller is scaled and added to $P_{R}$. The scaling factor, $K_{S O C}$, is set so that the change in the wind turbine's active power output is equal, and opposite, to the change in active power output from the BESS. The scaling factor, $K_{S o C}$, is determined by the ratio of the BESS active power rating, $P_{\max \_ \text {BESS, }}$ to the wind turbine's maximum power output,

$$
K_{\text {SoC }}=\frac{\mathrm{P}_{\text {max_BESS }}}{\mathrm{P}_{\text {max_WT }}}
$$

$\mathrm{P}_{\max \_ \text {wT }}$ is the maximum power available from the wind turbine when the blade pitch angle is $0^{\circ}$. Setting $K_{S O C}$ according to (5) means that the change in the wind turbine's active power output is equal to the change in active power output from the BESS resulting from accelerated SoC recovery. 


\section{$5 \quad$ Power System Model}

394 The performance of the accelerated SoC recovery scheme was assessed in DIgSILENT PowerFactory using the IEEE 39-bus model. The model represents the New England power system [30], [31] and consists of 10 synchronous generators, G01-G10, with G01 representing interconnection with a much larger power system. The model was modified to include wind generation and BESS by replacing the synchronous generator G07 with a wind farm and BESS as shown in Figure 10.

400

401

402

403

404

405

406

407

408

409

410

411

412

413

414

415

416

417

418

419

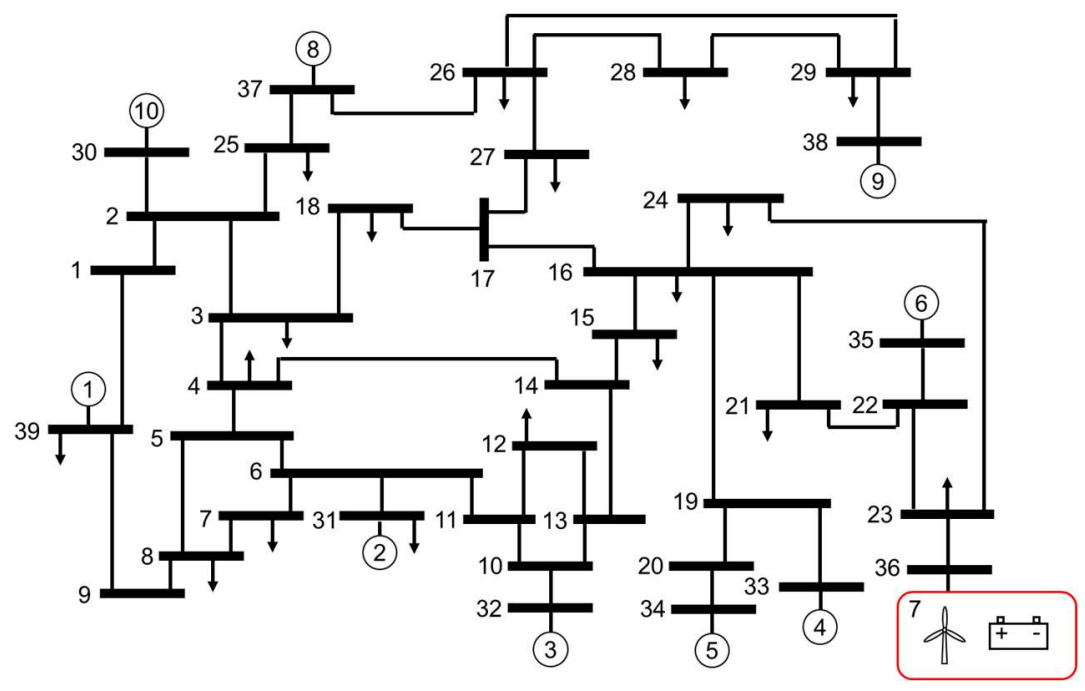

Figure 10. IEEE 39-bus power system model modified to include wind generation and BESS

The generator to be replaced with the wind farm was selected arbitrarily. The wind farm was modelled as $250 \times 6 \mathrm{MW}$ DFIG wind turbines operating in parallel according to the same control scheme. Using this modelling technique, the wind farm is modelled as a single large DFIG, which is partially de-coupled from the grid frequency via a power electronic convertor. The active power setpoint of the wind turbine was set to $560 \mathrm{MW}$, which was the active power output of G07 in the load flow of the original model. This represents only $37.33 \%$ of the wind turbine's rated power output, which lies within the cubic region of its power tracking curve during simulations (i.e. the wind turbine operated below rated power and rated speed during simulations). The wind turbine model was initialised with a wind speed that enabled the wind turbine to provide $560 \mathrm{MW}$ output while providing $5 \%$ delta reserve.

The generator governors were modelled using the IEEEG1 governor model. The model was parameterized using the gain and time constant values outlined in Table 2. Brogan et al. [13], suggest that these parameters simulate the dynamics of the Irish power system. 


\begin{tabular}{llllllll}
\hline \hline & $\begin{array}{c}\text { Time } \\
\text { Constants (s) }\end{array}$ & & Gain & \multicolumn{2}{c}{$\begin{array}{c}\text { Time } \\
\text { Constants (s) }\end{array}$} & & Gain \\
\hline T1 & 0.15 & K & 15 & T1 & 0.2 & K & 5 \\
T2 & 1 & K1 & 0.35 & T2 & 1 & K1 & 0.3 \\
T3 & 0.6 & K2 & 0 & T3 & 0.6 & K2 & 0 \\
T4 & 12 & K3 & 0.2 & T4 & 0.6 & K3 & 0.25 \\
T5 & 0.8 & K4 & 0 & T5 & 0.5 & K4 & 0 \\
T6 & 0.6 & K5 & 0.3 & T6 & 0.8 & K5 & 0.3 \\
T7 & 1 & K6 & 0 & T7 & 1 & K6 & 0 \\
& & K7 & 0.15 & & & K7 & 0.15 \\
& & K8 & 0 & & & K8 & 0 \\
\hline \hline
\end{tabular}

421

422

423

424

425

426

427

428

429

430

431

432

433

434

435

436

437

438

439

440

441

442

443

444

445

The BESS rating was set to 30MVA. The Ah rating of the BESS was set according to the minimum response capacity of assets providing EFR, i.e. the BESS must be capable of supplying its rated power for a minimum of 15 minutes. The minimum number of cells in parallel to meet this requirement was calculated as,

$$
N_{P}=\frac{S_{\max }}{\left(V_{c \max }+V_{c \min }\right) \times N_{S} \times Q_{c}}
$$

where, $S_{\max }$ is the apparent power rating of the BESS, $V_{c \max }$ is the maximum cell voltage, $V_{c m i n}$ is the minimum cell voltage, $N_{s}$ is the number of cells in series, and $Q_{c}$ is the Ah rating of each cell. The following parameters were used for the BESS model, $S_{\max }=30 \mathrm{MVA}, V_{c \max }=13.85 \mathrm{~V}$, $V_{c m i n}=12 \mathrm{~V}, N_{s}=65, N_{p}=223$, and $Q_{c}=80 \mathrm{Ah}$.

\section{$6 \quad$ Results and Analysis}

The results and analysis section is divided into two parts. Section 6.1 presents the results and analysis for the fuzzy logic simulations, which were performed using a time series frequency sample recorded by National Grid Electrical System Operator [32]. Section 6.2 presents the results of the accelerated SoC recovery simulations performed under constant wind speed conditions.

\subsection{Fuzzy Logic Control}

The fuzzy logic controller was tested under variable frequency conditions in DIgSILENT PowerFactory using a frequency sample recorded by National Grid Electricity System Operator [32]. The frequency sample was used as the frequency input to the BESS active power controller (Figure 3), and the response of the controller assessed. The following two cases are presented.

Case 1: 1\% frequency-droop control, without fuzzy logic control.

When operated without the fuzzy logic controller, the BESS does not make corrective changes to its power flow to restore nominal SoC. It responds only to deviations in system frequency outside the $\pm 0.015 \mathrm{~Hz}$ dead-band. It does this according to a $1 \%$ frequency-droop characteristic. 
447 In addition to responding to frequency deviations according to a $1 \%$ frequency-droop 448 characteristic, the BESS makes corrective changes to its power flow to restore the SoC to 449 nominal based on SoC and system frequency deviation measurements. Both Case 1 and Case 2 450 meet the requirements of EFR as outlined in Section 2.

\subsubsection{SoC initialised at 0.5 p.u.}

452 Figure 11 shows the results of a 2-hour simulation performed in DIgSILENT PowerFactory 453 when the $\mathrm{SoC}$ was initialised at $0.5 \mathrm{pu}$. The traces in dashed red are the results of Case 1, while 454 the traces in solid blue are those for Case 2.
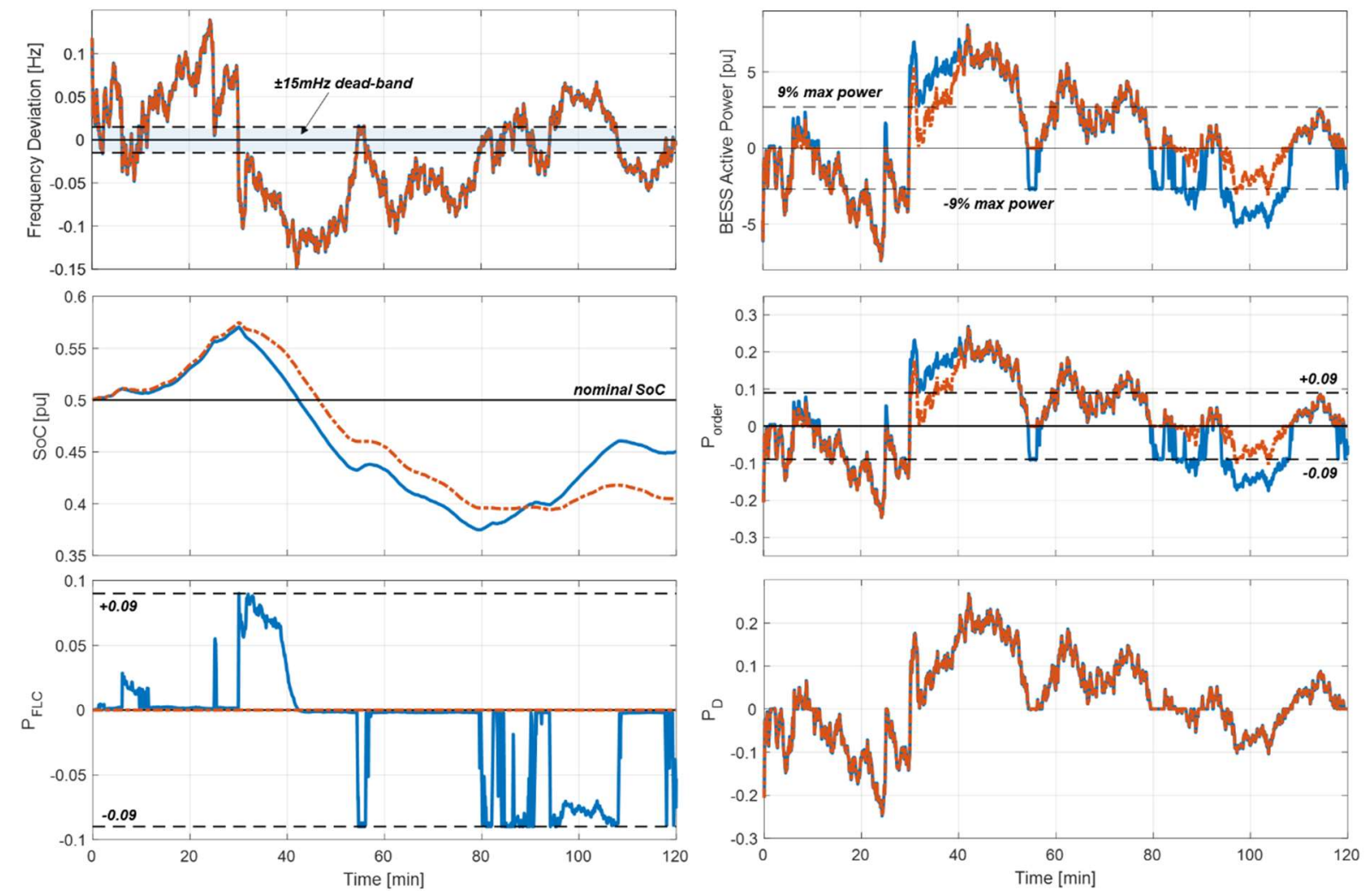

Figure 12 shows 10-minute results samples, which more clearly shows the response of the fuzzy logic controller to the variable frequency sample when the SoC is below nominal (Figure 12(a)) 


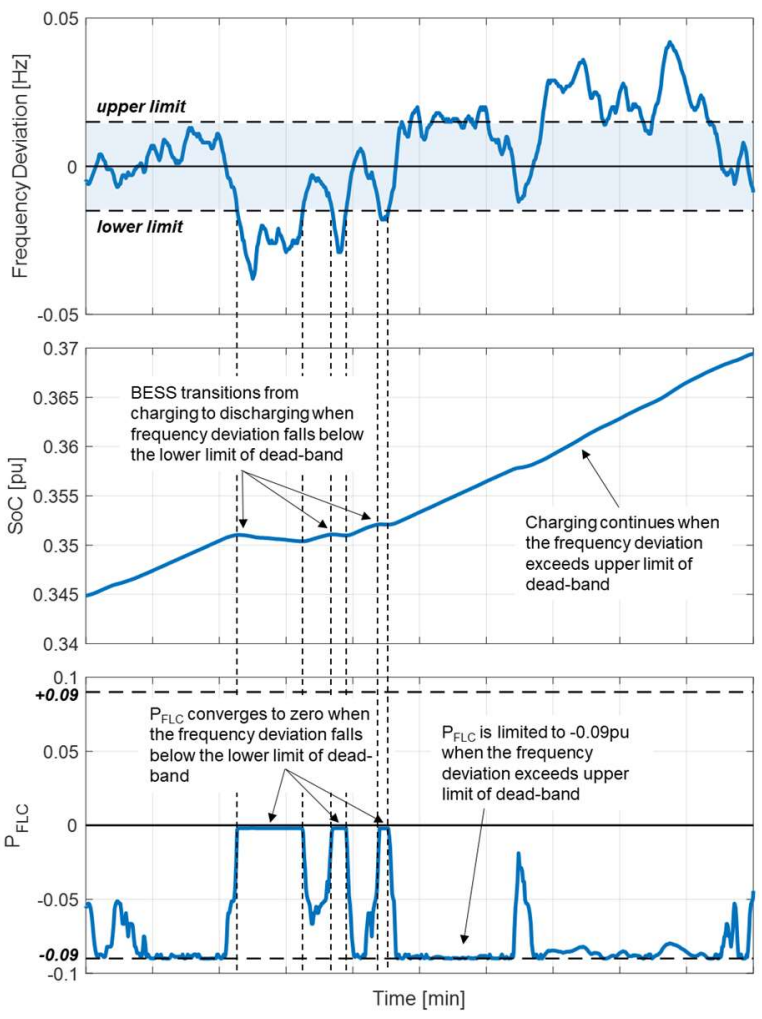

(a)

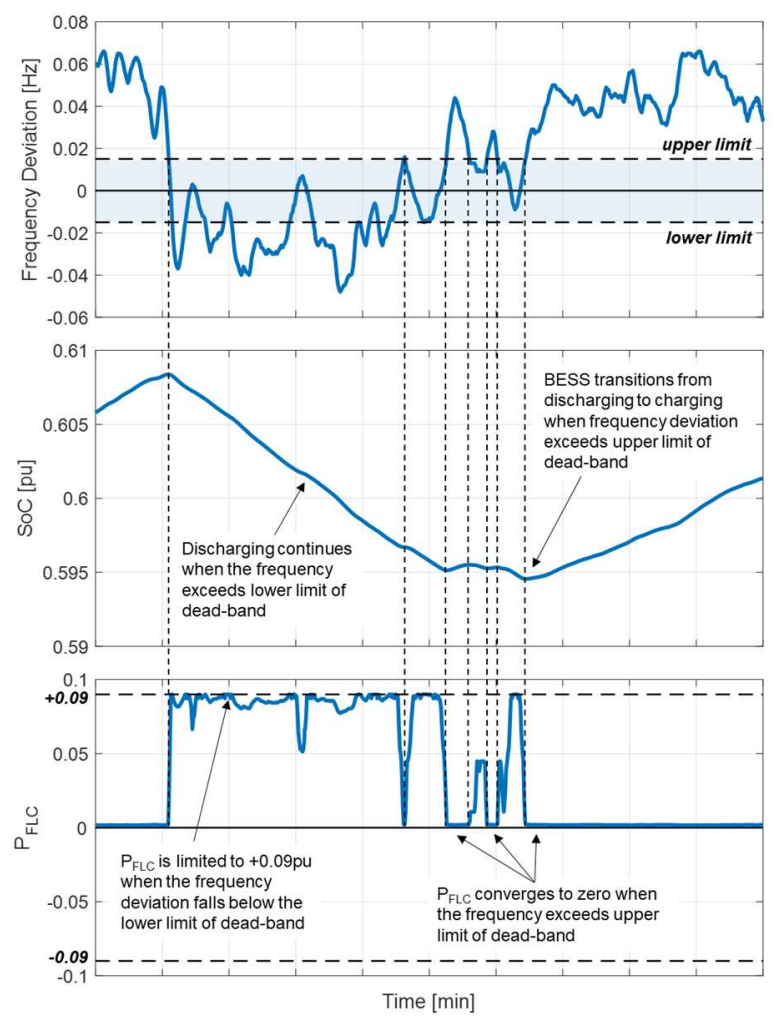

(b)

Figure 12. Fuzzy logic controller results: (a) SoC below nominal (b) SoC above nominal

\subsubsection{Fuzzy logic control: SoC above nominal}

When the system frequency deviation is within the dead-band, the BESS discharges proportionally to the deviation from nominal SoC only (i.e. the BESS does not respond to changes in frequency). The fuzzy logic controller provides corrective changes to the BESS power flow to restore nominal SoC. When the system frequency deviation falls below the lower limit of the dead-band, the fuzzy logic controller causes the BESS to discharge in response to both $\mathrm{SoC}$ deviation and frequency deviation. This is evident between 30 and 40 minutes in Figure 11. Under-frequency events occur when system generation is lower than load demand. In such situations, a BESS should discharge to reduce the imbalance. It can be noted that the fuzzy logic controller remains active when the frequency deviation is outside the dead-band, which allows the BESS to utilise its additional discharge capacity to accelerate the restoration of the nominal $\mathrm{SoC}$, while providing additional under-frequency regulation. When the frequency deviation reaches the upper limit of the dead-band, the output of the fuzzy logic controller, $P_{F L C}$, converges to zero. This is important because the BESS transitions from discharging to charging at the upper limit of the frequency deviation dead-band. If $P_{F L C}$ did not converge to zero, then the fuzzy logic controller would attenuate the frequency-droop response of the BESS. When the frequency deviation exceeds the upper limit of the dead-band, the BESS charges in response to frequency deviation only. The fuzzy logic controller has no effect on the BESS's power flow when the SoC is high and the frequency deviation is above the upper limit of the dead-band.

\subsubsection{Fuzzy logic control: SoC below nominal}

When the frequency deviation is within the dead-band, the BESS charges proportionally to SoC deviation to restore nominal SoC. When the frequency deviation exceeds the upper limit of the 
dead-band, the BESS charges in response to both SoC deviation and frequency deviation. This utilises the additional charge capacity of the BESS to accelerate nominal SoC restoration, while enhancing the BESS's contribution to over-frequency regulation. This is evident between 95 and 108 minutes in Figure 11. When the SoC is below nominal, the BESS transitions from charging to discharging when the frequency deviation falls below the lower limit of the deadband $\left(P_{F L C}\right.$ converges to zero when the system frequency deviation reaches the lower limit of the dead-band). The BESS discharges in response to frequency deviation only when the frequency deviation is below the lower limit of the dead-band. Therefore, the fuzzy logic controller has no effect on the BESS's frequency regulating response to under-frequency events when the SoC is below nominal.

\subsubsection{Low SoC: SoC initialised at 0.4pu}

Figure 13 shows the results when the BESS SoC was initialised at $0.4 \mathrm{pu}$. It can be noted that the $\mathrm{SoC}$ increases more rapidly when the fuzzy logic controller is used. With the fuzzy logic controller employed, the BESS utilises its additional charge capacity during over-frequency events to restore the $\mathrm{SoC}$ towards nominal, whilst providing additional over-frequency regulation. It can be noted that the SoC stays closer to nominal when the fuzzy logic controller is employed, which increases the availability to respond to frequency contingencies.
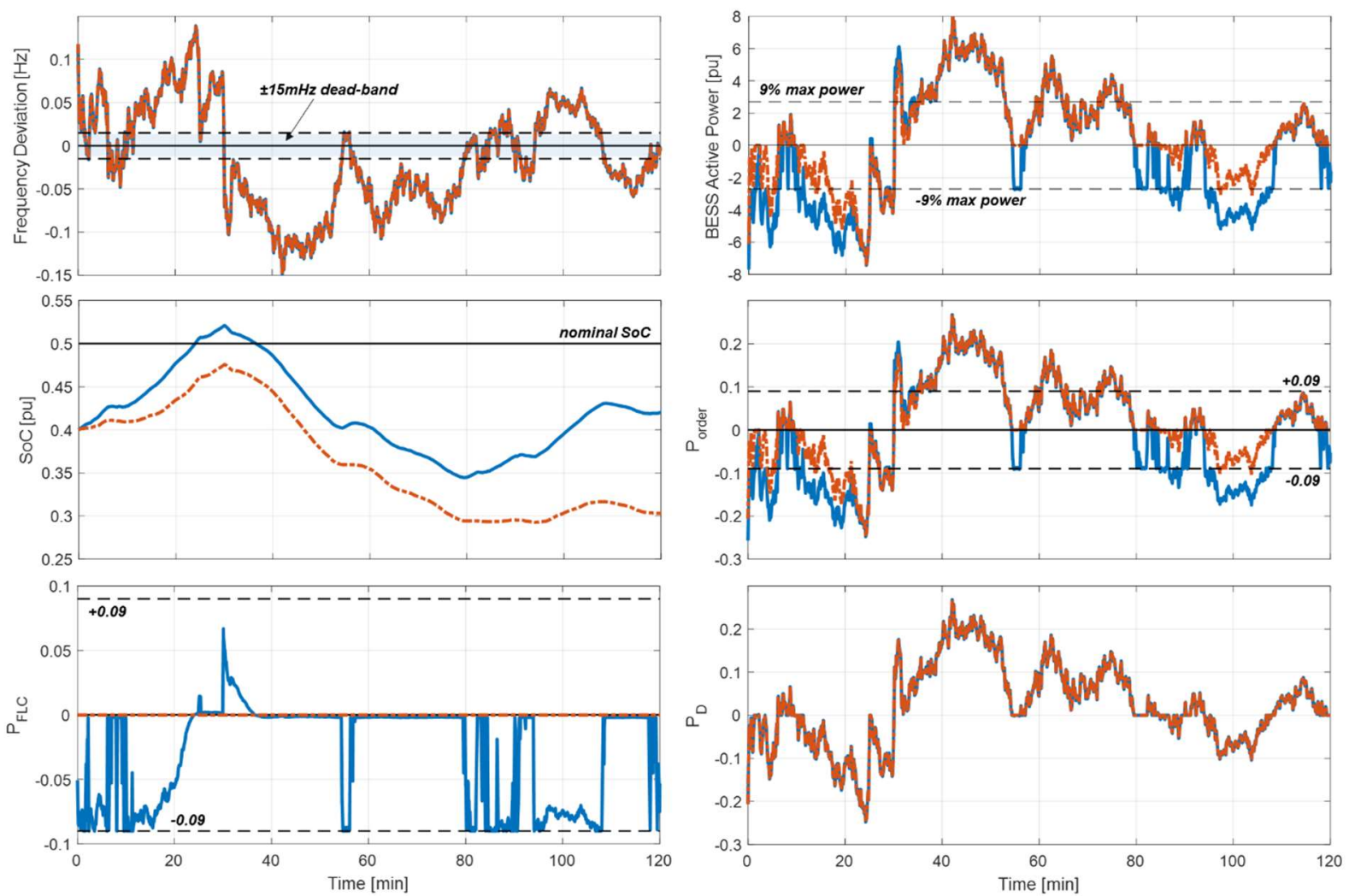

-With Fuzzy logic control ------Without Fuzzy logic control

Figure 13. Variable frequency results: SoC initialised at $0.4 p u$

\subsubsection{High SoC: SoC initialised at 0.6pu}

509 Figure 14 shows the results produced when the $\mathrm{SoC}$ is initialised at $0.6 \mathrm{pu}$. It can be noted that 510 the BESS uses its additional discharge capacity to increase its active power response to under- 
511 frequency conditions by remaining active when the frequency deviation falls below the lower 512 limit of the dead-band.
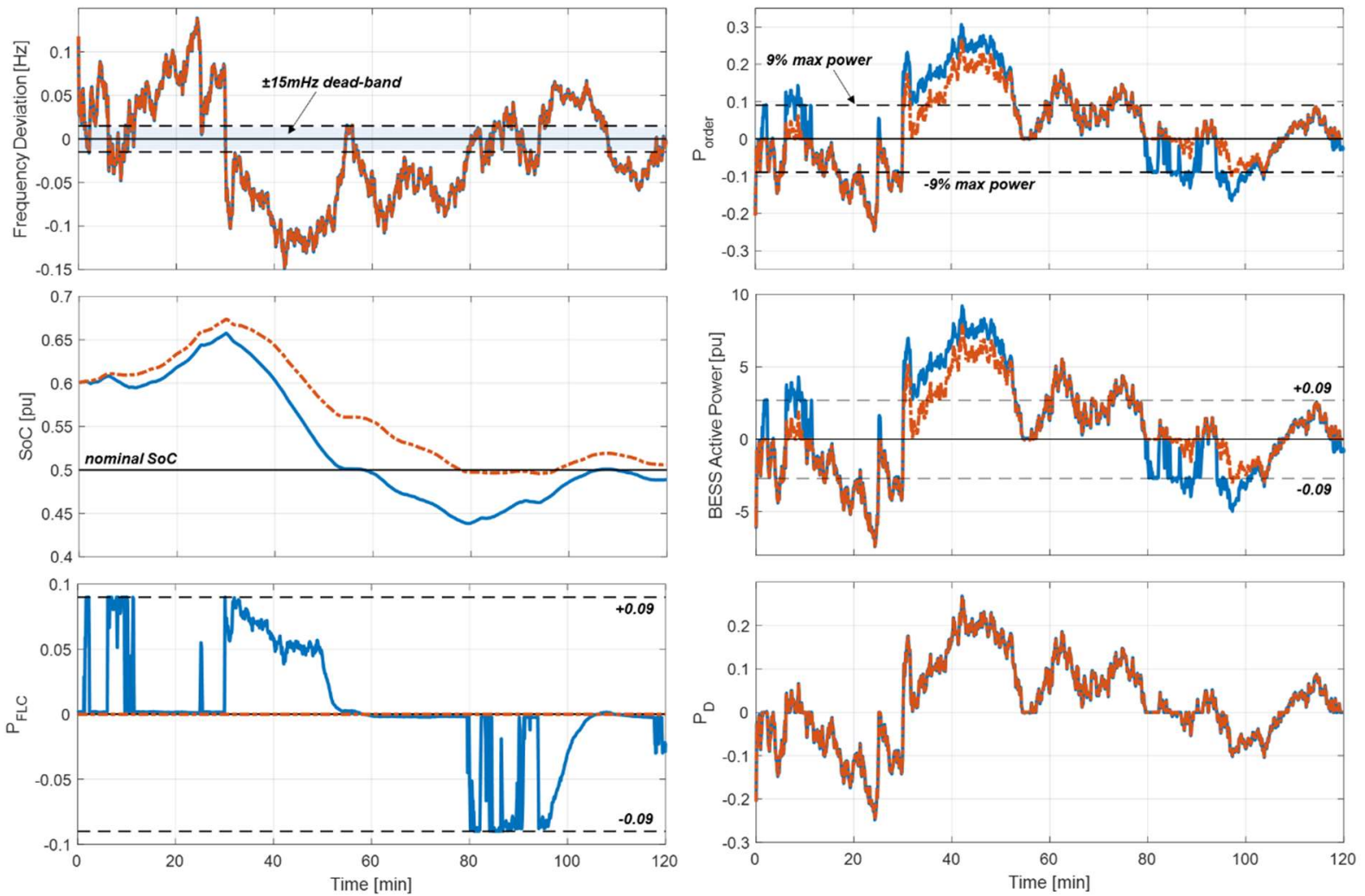

Figure 14. Variable frequency results: SoC initialised at $0.6 \mathrm{pu}$

Figure 15 shows that the BESS operates within the confines of the EFR service 2 envelope. When the fuzzy logic controller is employed, the BESS utilises any additional charge/discharge capacity, by operating at the extremes of the service envelope (i.e. the outer confines of the service envelope) to accelerate the restoration of nominal charge, while enhancing its frequency regulating response.
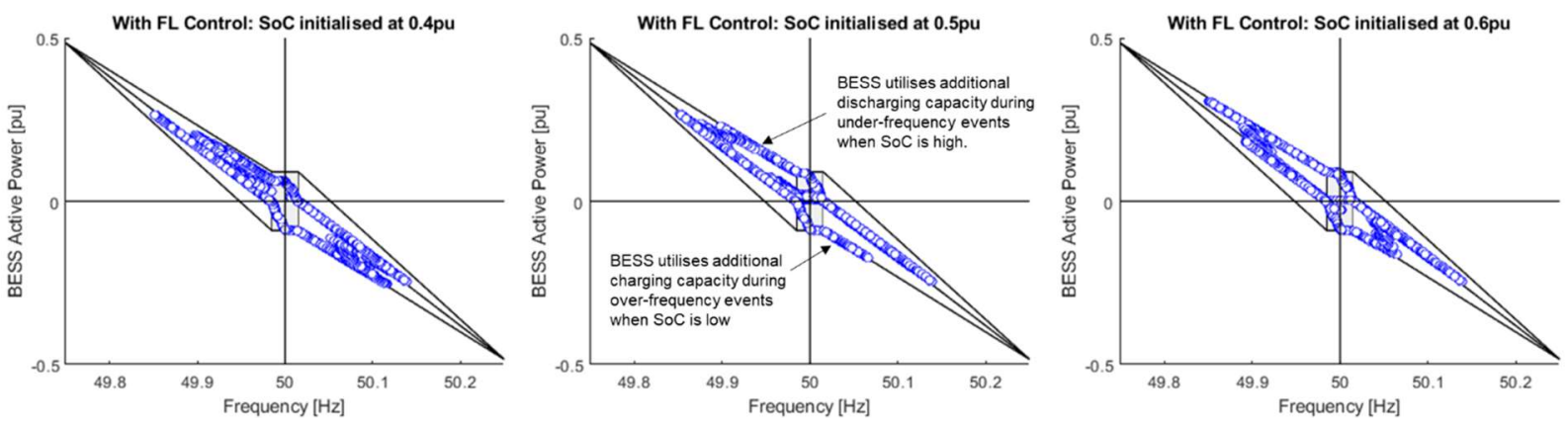

Figure 15. BESS active power vs system frequency response and EFR service 2 envelope. The blue circles represent the BESS active power output in response to the system frequency 


\subsection{Accelerated State of Charge Recovery}

526 The accelerated SoC recovery control scheme was simulated in DIgSILENT PowerFactory 527 under constant wind speed conditions. A dispatch signal was used to activate the scheme at $\mathrm{t}=$

5281 minute. Firstly, the simulations were performed where the BESS and wind turbine were controlled autonomously. Then, the same simulation parameters were used with hybrid dispatch control enabled. The results of the simulations are presented in the following sub-sections.

\subsubsection{Constant Wind Speed: Low SoC (SoC initialised at 0.2pu)}

Figure 16 compares the results produced when the SoC was initialised at $0.2 \mathrm{pu}$. The results show that there is no difference in the BESS active power and SoC trajectories for the two cases. Autonomous control, however, had significant impact on the system frequency. The frequency fell below the lower limit of the dead-band, which resulted in the activation of the wind turbine and BESS frequency-droop controllers.

As expected, autonomous control had almost no impact on the wind turbine's active power output. The slight increase exhibited is due to the significant drop in system frequency activating the wind turbine's frequency-droop response as opposed to a change to wind turbine dispatching. With hybrid dispatch control, the wind turbine increases its active power output to match the BESS charging power, which reduces the impact on system frequency. The system frequency stayed within the dead-band during accelerated SoC recovery when hybrid dispatch control was used, which meant that activation of primary response schemes was avoided.

544 It can be noted that the SoC increases from $0.2 \mathrm{pu}$ to $0.5 \mathrm{pu}$ in approximately 20 minutes. The 545 charging period can be controlled by changing the slope of the ramp function in the setpoint controller (see Figure 6) and the gains of the proportional-integral controller. If the charging power was limited to $9 \%$ of the maximum power as is the requirement for EFR, then it would take a minimum of 100 minutes to restore the SoC from $0.2 \mathrm{pu}$ to $0.5 \mathrm{pu}$. 

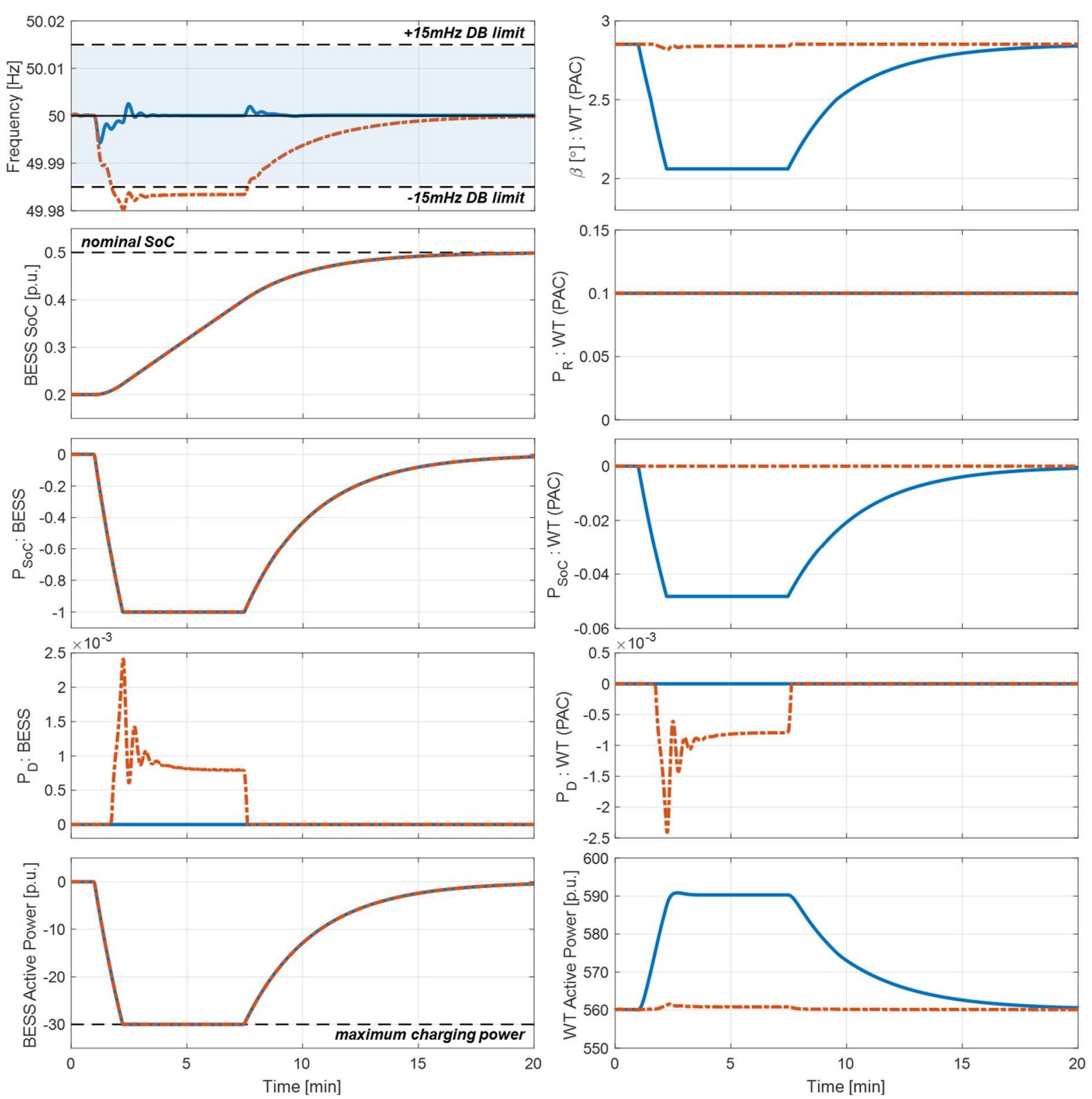

Figure 16. Accelerated SoC recovery results: $\mathrm{SoC}$ initialised at $0.2 \mathrm{pu}$

\subsubsection{Constant Wind Speed: High SoC (SoC initialised at 0.8pu)}

553 Figure 17 compares the results produced when the SoC was initialised at $0.8 \mathrm{pu}$. Like the results for the low SoC simulations, the trajectories of the BESS active power output and SoC are identical for the two cases. The results show that the system frequency does not exceed the dead-band when hybrid dispatch control is used, meaning that the activation of primary response schemes was avoided. With hybrid dispatch control, the wind turbine's active power output is decreased by an amount equivalent to the BESS discharging power, which reduces the impact on the system frequency. 

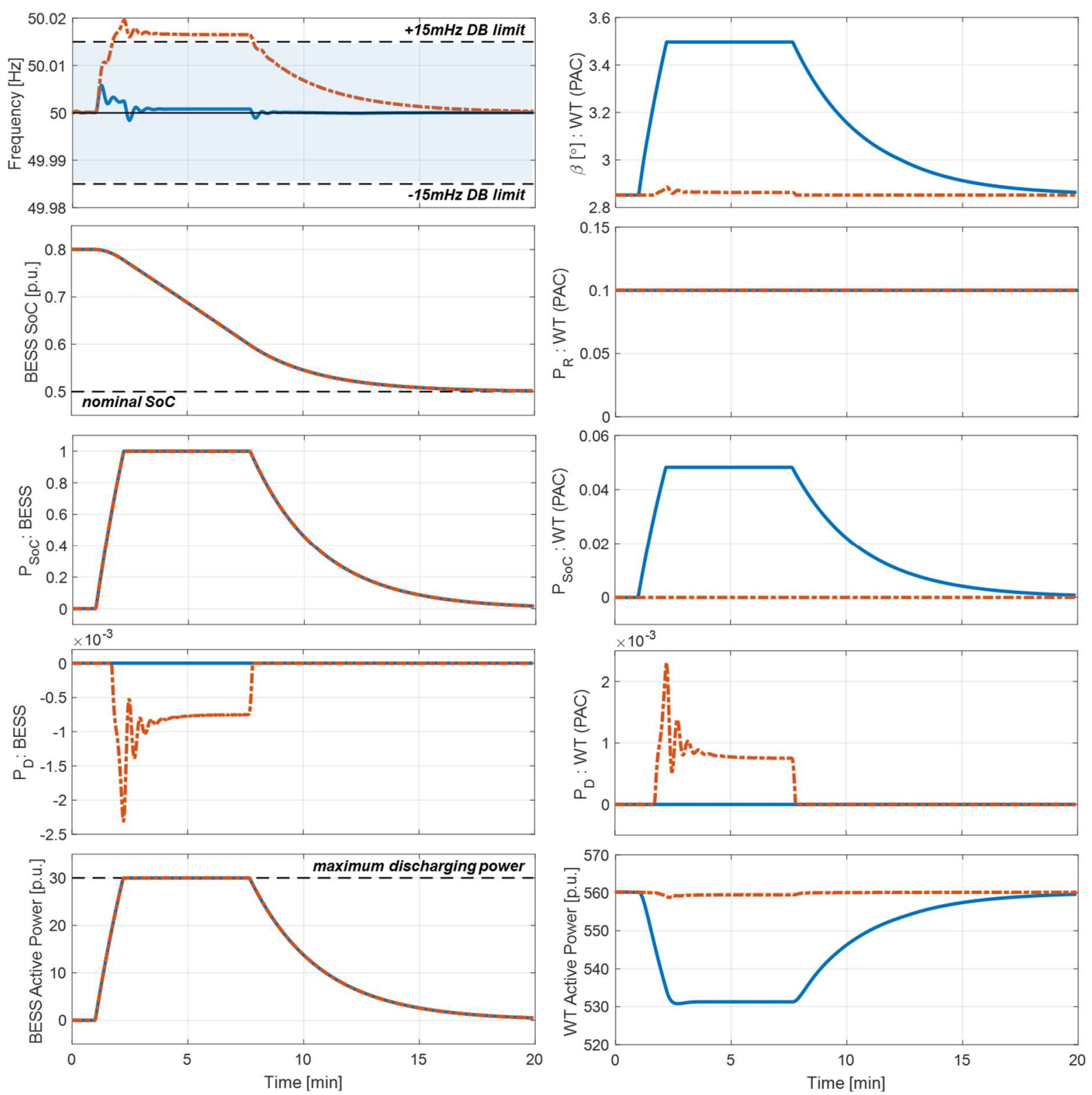

Figure 17. Accelerated SoC recovery results: SoC initialised at 0.8pu

\subsubsection{Response to contingency when charging}

A frequency event was simulated during accelerated SoC recovery to investigate the impact on the wind farm's frequency response performance (the wind farm consists of the wind turbine and BESS). Accelerated SoC recovery was initiated at $\mathrm{t}=1$ minute. An under-frequency event was created by suddenly connecting a 100MW load to busbar 16 at $t=3$ minutes. The results are compared to those produced without the initiation of accelerated SoC recovery in Figure 18. The results show that accelerated SoC recovery has almost no impact on the system frequency response. The charging power of the BESS during accelerated SoC recovery is compensated for by the increase in the wind turbine's power output. It can be noted that the wind farm's active power output is almost identical for both cases, there only being a slight dip in the wind farm's output when accelerated SoC recovery is first initiated. 

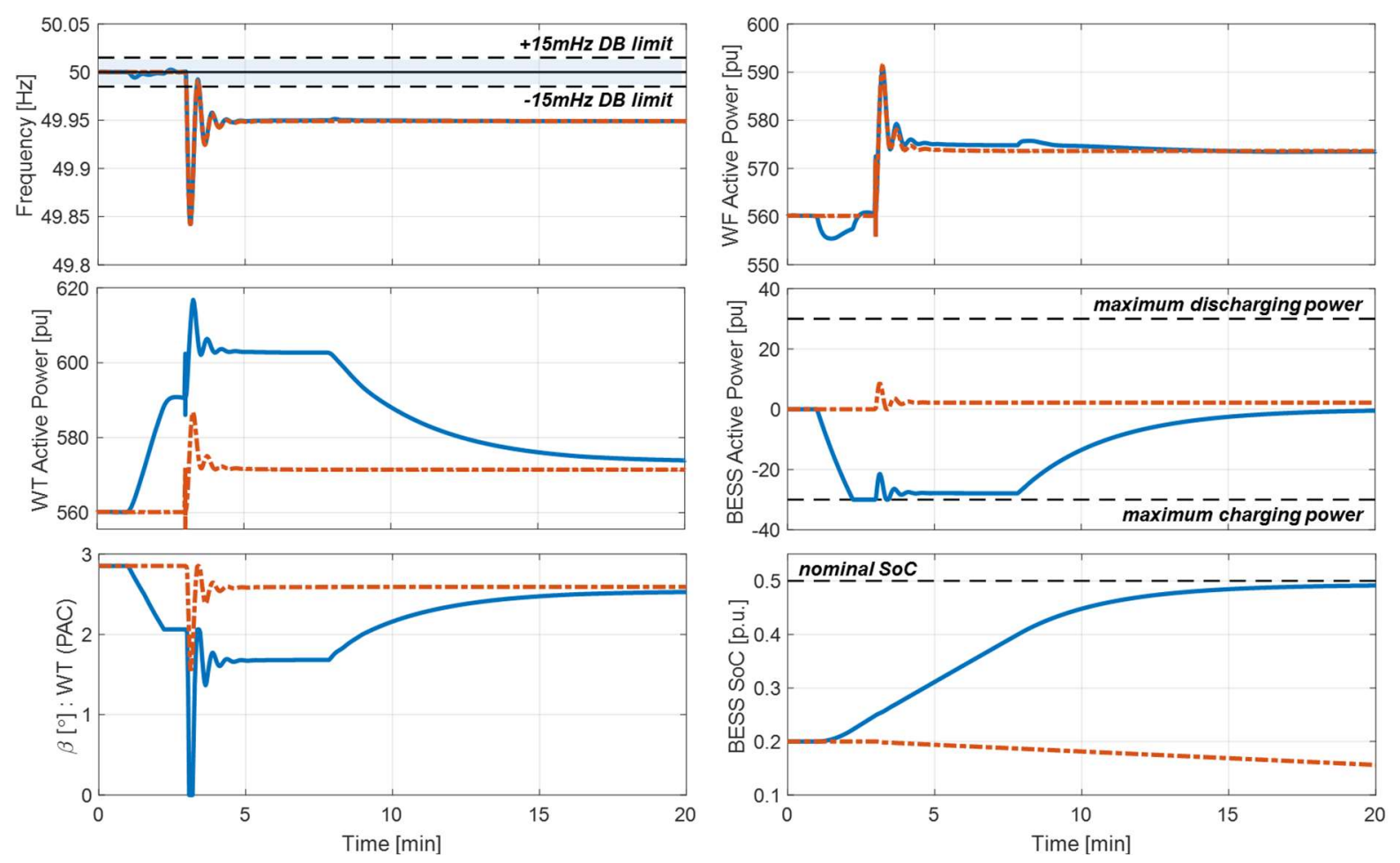

Figure 18. Response to frequency contingency. Accelerated SoC recovery initiated at $t=1$ minute. Underfrequency event initiated at $\mathrm{t}=\mathbf{3}$ minutes

\section{Discussion}

The results show that the proposed fuzzy logic controller effectively operated within the confines of the EFR service 2 envelope when tested under variable frequency simulations. The improvement of this control scheme over others in published research literature is that the controller remains operational outside of the $\pm 0.015 \mathrm{~Hz}$ dead-band, to utilise any additional charge/discharge capacity. This accelerates nominal SoC recovery, while also providing additional frequency support. It should be noted that though the additional charge/discharge responses would have a positive effect on the frequency dynamics, this is not reflected in the simulation results presented in figures 10-13. This is because a time series frequency sample was used to assess the performance of the fuzzy logic controller, hence the simulation results presented do not assess the dynamic frequency support offered by the BESS. The aim of the research is to prove that the controller is effective at re-establishing nominal charge. Future work will involve performing dynamic frequency simulations to assess the enhanced frequency support performance of the BESS when operated according to the proposed control scheme.

When the SoC is below nominal, the BESS has impaired capacity to respond to under-frequency events, while having increased capacity to respond to over-frequency events. Though the fuzzy logic controller makes use of this increased charge capacity to restore nominal SoC when the system frequency exceeds the nominal frequency, the impaired charging capacity of the BESS is a concern. It is imperative that the nominal SoC is restored as quickly as possible to ensure availability and reliability of frequency regulating services. A similar situation exists when the $\mathrm{SoC}$ is greater than nominal, with the BESS having impaired charging capacity to over- 
frequency events. Though this condition may not be as serious as the former because committed generating units can down-dispatch to restore nominal frequency in the case of a significant over-frequency event.

603 The research highlights the requirement for accelerated SoC restoration. This is something that 604 has been neglected in published research literature in this field. State of charge recovery schemes that operate within the confines of the EFR service envelope will incur long periods where the BESS has reduced capacity after service delivery (i.e. long periods were the SoC is above or below nominal). If BESSs are to avoid system performance measurement nonperformance penalties, then their SoC must be kept close to nominal. Long restoration times after significant charging or discharging will result in reduced availability. If the availability is to be improved, then there must be a way to reduce the time it takes to restore nominal charge, without significantly impacting the system frequency.

The results presented in Section 6.2 show that the proposed accelerated SoC recovery controller is effective at accelerating the re-establishment of nominal SoC. Hybrid dispatch control can be used to reduce the impact that accelerated $\mathrm{SoC}$ recovery has on the system frequency. The simulation results show that the accelerated SoC recovery scheme is effective at restoring nominal charge within 20 minutes, which is at least 5 times faster than that which could be achieved with control schemes that operate within the confines of the EFR service envelope. Contingency simulations show that the scheme has very little impact on the wind farm's frequency response (the wind farm's response is taken to be the aggregate of the wind turbine and BESS power output).

\section{Conclusion}

This research presents an analysis of SoC management schemes for BESSs to restore nominal

SoC. The fuzzy logic controller presented was designed in MATLAB and implemented in DIgSILENT PowerFactory using a look-up table. Frequency simulations were performed using a time series frequency sample provided by the National Grid Electricity System Operator, to assess the performance of the proposed fuzzy logic controller. The simulation results presented show that the controller works to restore the SoC to nominal when the system frequency deviation is within the $\pm 0.015 \mathrm{~Hz}$ dead-band. The controller differs from other controllers in published research literature in that the BESS utilises any additional charge/discharge capacity to accelerate SoC restoration, even when the frequency deviation is outside the $\pm 0.015 \mathrm{~Hz}$ deadband (up to a limit of $\pm 0.25 \mathrm{~Hz}$ ). It does this by operating at the outer extremes of the EFR service envelope. The limitations of SoC management systems that operate within the confines of the EFR service envelope are highlighted, which led to the development of the accelerated SoC recovery control scheme proposed. An IEEE 39-bus test bed with type 3 DFIG wind turbine and BESS was built in DIgSILENT PowerFactory to assess the performance of the proposed accelerated SoC recovery control scheme. The analysis shows that nominal SoC was achieved 5 times faster than that which could be achieved using recovery controllers that operate within the confines of the EFR service envelope. Hybrid dispatch control of the wind turbine and BESS reduced the impact that accelerated $\mathrm{SoC}$ restoration had on the system frequency (the frequency did not deviate outside the $\pm 0.015 \mathrm{~Hz}$ dead-band). The ability to quickly restore nominal SoC to increase availability of system services, without significantly affecting system frequency, is a novel contribution to the published research literature in the field.

Overall, this research has demonstrated the ability of BESS to quickly restore nominal charge 
penetration of intermittent renewable generation is to continue to increase to significant levels. For this to be successful, BESSs must have a robust operational strategy, which ensures that the SoC remains at nominal most of the time. This is particularly important in countries such as Ireland, the United Kingdom, Italy, and Spain who have large wind power penetration and limited interconnection and or grid constraint/congestion problems. The research presented is limited by the availability of wind farm and BESS data, which is commercially sensitive. However, this limitation does not affect the key findings of the analysis presented. Future work will further investigate accelerated SoC recovery, to optimise performance based on SoC status decision making during frequency events. Another further piece of work, which could follow on to inform countries with large solar photovoltaic generation, would be to examine solar photovoltaic with BESS, and different controller configurations, as an option to diversify the renewable generation mix.

\section{Acknowledgements}

660

We would like to thank the organisers of the $14^{\text {th }}$ Conference on Sustainable Development of Energy, Water and Environment Systems (SDEWES) held in Dubrovnik for allowing us to present the initial findings of this research at their conference. The paper titled "Hybrid control of wind generation and energy storage to enhance wind farms' ability to provide system services" was presented on $06^{\text {th }}$ October 2019 . We would also like to thank the National Grid Electricity System Operator for making their time series frequency data available.

666

667

668

669

670

671

672

673

674

675

676

677

678

679

680

681

682

683

684

685

686

687

688

\section{References}

[1] Nga Nguyen and J. Mitra, "An analysis of the effects and dependency of wind power penetration on system frequency regulation," IEEE Transactions on Sustainable Energy, vol. 7, no. 1, pp. 354-363, Jan. 2016.

[2] M. Hajiakbari Fini and M.E. Hamedani Golshan, "Determining optimal virtual inertia and frequency control parameters to preserve the frequency stability in islanded microgrids with high penetration of renewables," Electric Power Systems Research, vol. 154, pp. 1322, Jan. 2018.

[3] Y. Liu, X. Wu, G. Wu, J. Du and Z. Song, "Optimal sizing of a wind-energy storage system considering battery life," Renewable Energy, vol. 147, pp. 2470-2483, Mar. 2020.

[4] EirGrid and SONI, "DS3 system services: Portfolio capability analysis," Nov. 2014.

[5] SEM committee, "DS3 system services procurement design and emerging thinking," Dec. 2014.

[6] C. Zhang, Y. Wei, P. Cao and M. Lin, "Energy storage system: Current studies on batteries and power condition system," Renewable and Sustainable Energy Reviews, vol. 82, part 3, pp. 3091-3106, Feb. 2018.

[7] H. Zhao, Q. Wu, S. Hu, H. Xu and C.N. Rasmussen, "Review of energy storage system for wind power integration support," Applied Energy, vol. 137, pp. 545-553, Jan. 2015.

[8] National Grid, "Enhanced frequency response: Invitation to tender for pre-qualified parties," July 2016.

[9] Y. Wu and K. Tang, "Frequency support by BESS - review and analysis," Energy Procedia, vol. 156, pp. 187-191, Jan. 2019. 
[10] Z. Wu, D. Wenzhong Gao, H. Zhang, S. Yan and X. Wang, "Coordinated control strategy of battery energy storage system and PMSG-WTG to enhance system frequency regulation capability," IEEE Transactions on Sustainable Energy, vol. 8, no. 3, pp. 1330-1343, July 2017.

[11] S. Dhundhara and Y.P. Verma, "Grid frequency enhancement using coordinated action of wind unit with redox flow battery in a deregulated electricity market," International Transactions on Electrical Energy Systems, vol. 30, no. 3, pp. 1-33, Mar 2020.

[12] Z. Tan, X. Li, L. He, Y. Li and J. Huang, "Primary frequency control with BESS considering adaptive SoC recovery," International Journal of Electrical Power and Energy Systems, vol. 117, pp. 105588, May 2020.

[13] P.V. Brogan, R.J. Best, D.J. Morrow, K. McKinley and M.L. Kubik, "Effect of BESS response on frequency and RoCoF during underfrequency transients," IEEE Transactions on Power Systems, vol. 34, no. 1, pp. 575-583, Jan. 2019.

[14] J. Tan and Y. Zhang, "Coordinated control strategy of a battery energy storage system to support a wind power plant providing multi-timescale frequency ancillary services," IEEE Transactions on Sustainable Energy, vol. 8, no. 3, pp. 1140-1153, July 2017.

[15] A. Hoke, A. Brissette, D. Maksimovic, D. Kelly, A. Pratt and D. Boundy, "Maximizing lithium ion vehicle battery life through optimized partial charging," in 2013 IEEE PES Innovative Smart Grid Technologies Conference (ISGT), Washington, DC, Feb. 2013, pp. $1-5$.

[16] B. Mantar Gundogdu, S. Nejad, D.T. Gladwin, M.P. Foster and D.A. Stone, "A battery energy management strategy for U.K. enhanced frequency response and triad avoidance," IEEE Transactions on Industrial Electronics, vol. 65, no. 12, pp. 9509-9517, Dec 2018.

[17] P. Li, Z. Tan, Y. Zhou, C. Li, R. Li and X. Qi, "Secondary frequency regulation strategy with fuzzy logic method and self-adaptive modification of state of charge," Access, vol. 6 , pp. 43575-43585, July 2018.

[18] EirGrid and SONI, "Integration of battery energy storage systems to the ireland and northern ireland power systems," June, 2019.

[19] EirGrid, "EirGrid grid code version 8," June 14, 2019.

[20] SONI, "SONI grid code," June 26, 2019.

[21] C. Brivio, S. Mandelli and M. Merlo, "Battery energy storage system for primary control reserve and energy arbitrage," Sustainable Energy, Grids and Networks, vol. 6, pp. 152165, Jun 2016.

[22] R. Villena-Ruiz, A. Honrubia-Escribano, J. Fortmann and E. Gómez-Lázaro, "Field validation of a standard type 3 wind turbine model implemented in DIgSILENTPowerFactory following IEC 61400-27-1 guidelines," International Journal of Electrical Power and Energy Systems, vol. 116, pp. 105553, Mar 2020.

[23] D. Ochoa and S. Martinez, "Frequency dependent strategy for mitigating wind power fluctuations of a doubly-fed induction generator wind turbine based on virtual inertia control and blade pitch angle regulation," Renewable Energy, vol. 128, pp. 108-124, Dec. 2018.

[24] U. Datta, J. Shi and A. Kalam, "Primary frequency control of a microgrid with integrated dynamic sectional droop and fuzzy based pitch angle control," International Journal of Electrical Power and Energy Systems, vol. 111, pp. 248-259, Oct. 2019.

[25] X. Tang, M. Yin, C. Shen, Y. Xu, Z.Y. Dong and Y. Zou, "Active power control of wind turbine generators via coordinated rotor speed and pitch angle regulation," IEEE Transactions on Sustainable Energy, vol. 10, no. 2, pp. 822-832, Apr. 2019. 
[26] S. Siniscalchi-Minna, F.D. Bianchi, M. De-Prada-Gil and C. Ocampo-Martinez, "A wind farm control strategy for power reserve maximization," Renewable Energy, vol. 131, pp. 37-44, Feb. 2019.

[27] A.B. Attya, J.L. Dominguez-Garcia and O. Anaya-Lara, "A review on frequency support provision by wind power plants: Current and future challenges," Renewable and Sustainable Energy Reviews, vol. 81, pp. 2071-2087, Jan. 2018.

[28] I.D. Margaris, S.A. Papathanassiou, N.D. Hatziargyriou, A.D. Hansen and P. Sorensen, "Frequency control in autonomous power systems with high wind power penetration," IEEE Transactions on Sustainable Energy, vol. 3, no. 2, pp. 189-199, Apr. 2012.

[29] S. Heier, Grid integration of wind energy conversion systems, 2nd ed. Chichester, John Wiley \& Sons Ltd, 2006.

[30] M.A. Pai, Energy function analysis for power system stability, 1st ed. Boston, Kluwer, 1989.

[31] DIgSILENT PowerFactory, 39 bus New England system.

[32] National Grid. Historic frequency data [Online]. available: https://www.nationalgrideso.com/balancing-services/frequency-responseservices/historic-frequency-data. 